The Value of Socialized Medicine: The Impact of Universal Primary Healthcare Provision on Birth and Mortality Rates in Turkey

\author{
Resul Cesur \\ University of Connecticut \\ cesur@business.uconn.edu
}

\author{
Pınar Mine Güneş \\ University of Alberta \\ gunes@ualberta.ca
}

Erdal Tekin

American University, IZA, and NBER

tekin@american.edu

Aydogan Ulker

Deakin University

ulker@,deakin.edu.au

August 2015

We thank Dr. Emel Ergün Seyit for providing insights about the operational details of the family medicine program and participants at the European Society for Population Economics for their helpful comments and suggestions. 


\title{
The Value of Socialized Medicine: The Impact of Universal Primary Healthcare Provision on Birth and Mortality Rates in Turkey
}

\begin{abstract}
This paper examines the impact of universal, free, and easily accessible primary healthcare on population health as measured by age-specific birth and mortality rates, focusing on a nationwide socialized medicine program implemented in Turkey. The Family Medicine Program (FMP), launched in 2005, assigns each Turkish citizen to a specific state-employed family physician, who offers a wide range of primary healthcare services that are free-of-charge. Furthermore, these services are provided at family health centers, which operate on a walk-in basis and are located within the neighborhoods in close proximity to the patients. To identify the causal impact of the FMP, we exploit the variation in its introduction across provinces and over time. Our estimates indicate that the FMP caused large declines in mortality rates across all age groups with more pronounced impacts among infants and the elderly, and a moderate reduction in the birth rates, primarily among teenagers. Furthermore, the results are suggestive that the program has also contributed towards equalization in the mortality disparities across provinces. Our findings highlight the importance of a nationwide supplyside intervention on improving public health.
\end{abstract}


"I regard universal health coverage as the single most powerful concept that public health has to offer. It is inclusive. It unifies services and delivers them in a comprehensive and integrated way, based on primary healthcare."

-Dr. Margaret Chan, WHO Director-General, December $2012^{1}$

\section{Introduction}

One of the most daunting challenges faced by governments around the world is how to expand adequate and basic healthcare services to all of their citizens. According to the World Health Organization (WHO), there are about 1.3 billion people in the world lacking effective and affordable medical care. ${ }^{2}$ Majority of these people live in developing countries, which confront an especially steep challenge as they face a shortage of trained healthcare personnel, infrastructure, and financial resources necessary to establish a universal healthcare system. ${ }^{3}$

Despite these challenges, an increasing number of countries are devising reforms aimed at improving public health and reducing disparities in the delivery of and access to basic healthcare services. Many countries have taken a primarily demand-side approach to extending health coverage, through mechanisms such as health insurance, user-fees on the basis of ability-to-pay, and conditional cash transfers, for example China (Carrin et al., 1999; Wagstaff et al., 2009), Colombia (Arroyave et al., 2013; Giedion and Diaz, 2010; Ruiz et al., 2007), Costa Rica (Cercone et al., 2010; Dow and Schmeer, 2003), Mexico (Pfutze, 2014; Sosa-Rubi et al., 2009), Peru (Bernal et al., 2014; Bitrán et al., 2010), Taiwan (Cheng and Chiang, 1997), and Vietnam (Ekman et al., 2008; Somanathan

\footnotetext{
${ }^{1}$ Opening remarks at a member state consultation on health in the post-2015 development agenda Geneva, Switzerland. See http://www.who.int/dg/speeches/2012/mdgs post2015/en/ for the full speech.

${ }^{2}$ See http://www.who.int/bulletin/volumes/86/11/07-049387/en/.

${ }^{3}$ Recognizing this challenge, the member states of WHO passed a resolution in 2005 , encouraging countries to reform their health-financing systems with the goal of achieving universal coverage (WHO, 2005).
} 
et al., 2013). There are also countries that have opted for mainly supply-side schemes by extending government financed public provision of healthcare services or creating incentive mechanisms that financially motivate providers to expand their coverage. Two well-known examples that fall into this category are Thailand (Gruber et al., 2014) and Brazil (Aquino et al., 2009; Macinko et al., 2006; Paim et al., 2011; Rocha and Soares, 2010). The emerging consensus from the strand of the literature that focuses on the demand-side healthcare financing reforms is that extending health insurance coverage improves both access and utilization, at least among the targeted groups. However, the evidence on the degree to which these interventions limit out of pocket expenditures for services and improve health outcomes is mixed and inconclusive. ${ }^{4}$ The relatively few studies that have focused on supply-side reforms, on the other hand, find that increased availability of free or heavily subsidized healthcare improves both access and health outcomes (Gruber et al., 2014; Rocha and Soares, 2010).

In this paper, we study the impact of a supply-side healthcare intervention implemented in Turkey on measures of mortality and birth rates. The Family Medicine Program - called FMP hereafter - introduced in 2005, has extended basic healthcare services to the entire Turkish population under a free-of-charge and single-payer system that is fully financed and administered by the central government. The key operational feature of the FMP is the assignment of each Turkish citizen to a specific family physician, who offers a wide range of basic healthcare services at easily accessible walkin clinics called the Family Health Centers. The program was first initiated as a pilot in 2005 in the province of Düzce, and gradually expanded to cover the entire Turkish

\footnotetext{
${ }^{4}$ See Giedion and Diaz (2010) and Nicholson et al. (2015) for a discussion.
} 
population living in all 81 provinces by the end of $2010 .{ }^{5}$ Currently, the FMP provides healthcare services to all Turkish citizens and staffs over 21,217 family physicians - all public employees - in 6,768 and 971 family and community health centers, respectively. ${ }^{6}$

There are a number of motivating factors for our analysis. First, there is evidence crediting the FMP with increased patient satisfaction and healthcare utilization (Baris et al., 2011; WHO, 2008), but there has not been a rigorous evaluation of the program impact on measures of health outcomes yet. This is despite the scope and the scale of the Turkish program that makes it arguably one of the most ambitious and comprehensive efforts to achieve universal health coverage in a developing country.

Second, there are a number of distinct features that separates the FMP from the aforementioned interventions implemented by other countries, most of which are already studied extensively. Most importantly, the Turkish reform has essentially established a socialized medicine program for basic healthcare services since the services are provided free-of-charge by state-employed family physicians. This is in sharp contrast with most other interventions, especially those concerning demand-side incentives, which primarily focus on the impact of reducing out-of-pocket healthcare expenses. Additionally, there is a growing conviction among the leading global health organizations, policymakers and practitioners about the importance of achieving universal health coverage, i.e., ensuring basic and affordable healthcare services to whole citizens irrespective of their ability to pay (Nicholson et al., 2015; Rottingen et al., 2014; United Nations Sustainable Development Solutions Network, 2014; Wagstaff, 2014; WHO, 2014a). According to this view, a key step towards universal coverage is to extend an affordable and basic package

\footnotetext{
${ }^{5}$ Law No. 5258 on Family Medicine Pilot Implementation.

${ }^{6}$ See http://ailehekimligi.gov.tr.
} 
of services to all citizens as opposed to an approach that prioritizes specific populations (e.g., the poorest in the society or people in informal employment) by offering them a broader range of services (Nicholas et al., 2015; Rottingen et al., 2014). However, this endorsement mainly comes from the failure of insurance-based interventions in achieving universal coverage or improving health outcomes and the evidence drawn from the relatively small-scaled randomized controlled trials conducted in poor or developing countries. Investigations of large-scale or nationwide reforms are scarce simply because such interventions are rare. Therefore, the Turkish FMP presents a unique opportunity to provide insights into the impact of a nationwide supply-side intervention on population health.

Additionally, most of the existing literature studying public health systems and their impact on health outcomes focus on demand-side interventions while rigorous evaluations of supply-side programs are relatively rare. Therefore, by highlighting the importance of the FMP on population health, our study also contributes to a momentum in supply-side investigations in the literature reflected by a number of recent studies focused on reforms in the contexts of Brazil (e.g., Reis, 2014; Rocha and Soares, 2010) and Thailand (e.g., Gruber et al., 2014).

Exploiting the gradual program rollout across provinces and over time in a difference-in-differences framework, we examine the effect of the FMP on age-specific birth and mortality rates in Turkey for the period of 2001-2013. Our results indicate that the FMP led to considerable health benefits. In particular, we find that the FMP caused a large and statistically significant decline in overall mortality rate with more pronounced 
and long-lasting effects among infants and the elderly. We also find that the FMP reduced the birth rates, especially among teenagers.

Our paper proceeds as follows. In Section II, we provide a review of the literature. Section III presents a background on the Turkish FMP program. Section IV introduces the data and Section V describes the empirical strategy. In Section VI, we present the estimates of the impact of the FMP on age-specific birth and mortality rates. Finally, Section VII concludes.

\section{Literature}

Many low- and middle-income countries have introduced reforms to their healthcare systems with the goals of expanding medical care to broader populations, improving public health, and reducing disparities in healthcare delivery. ${ }^{7}$ On the one hand, some countries expanded health insurance coverage to economically disadvantaged populations (e.g., China in 2003, Columbia in 1993, Costa Rica in 1973, Japan in $1956^{8}$, Mexico in 2001, Peru in 2001, Taiwan in 1993). On the other hand, some others implemented healthcare reforms with a greater emphasis on supply-side interventions either through the direct provision of healthcare services (e.g., Brazil 1994) or creating strong incentives to the producers of medical care (e.g., Thailand 2001) to achieve the stated goals.

Studies examining the effects of demand-side reforms find strong evidence that insurance expansions increase access to medical care. However, the evidence on the extent to which these interventions have led to improved health is less certain. On the one

\footnotetext{
${ }^{7}$ For a survey of the literature on the major primary care initiatives and the costs of providing care in lowand middle-income countries, see Kruk et al. (2010).

${ }^{8}$ Note that Japan was a middle-income country during $1950 \mathrm{~s}$.
} 
hand, a group of studies document positive health effects associated with the expansion of health insurance coverage. For example, Sosa-Rubi et al. (2009) consider the Mexico's Seguro Popular program, which was launched in 2001 with the goal of providing health insurance to low income populations. Using a propensity score matching methodology, the authors show that the program improved access to healthcare and the likelihood of blood glucose control among poor adults with diabetes in Mexico, and it might have also had a positive effect on the management of other chronic health conditions. Using cross sectional micro data from the Mexico's 2010 census and a difference-in-differences econometric methodology, Pfutze (2014) documents that the Seguro Popular program reduced infant mortality. Camacho and Conover (2013) use program eligibility as an instrumental variable to examine the effect of Colombia's Subsidized Regime of 1993, which provides medical plans and some healthcare services for the poor, on access to medical care and birth outcomes. The authors find that receiving subsidized health insurance increased the likelihood of medical care utilization and reduced the incidence of low birth weight.

On the other hand, several studies focusing on a group of other countries suggest that insurance coverage expansions do not necessarily improve public health. One of the earliest large-scale health insurance expansions was implemented in Japan in 1956 with the aim of achieving universal health insurance coverage by 1961. Kondo and Shigeoka (2013) examine the effect of the reform on medical care utilization and mortality rates, relying on differences in baseline insurance coverage rates as the source of identifying 
variation. ${ }^{9}$ While they find that access to health insurance increased medical care utilization (i.e., admissions, inpatient days, and outpatient visits to hospitals), it did not affect age specific mortality rates.

As another example, Dow and Schmeer (2003) consider the health insurance expansion in Costa Rica, which started in 2001. Using a long-difference estimator to account for the county-level unobservable determinants of health as well as insurance coverage, the authors find little evidence to support the notion that access to health insurance lowers child mortality. Along similar lines, Lei and Lin (2009) study the impact of New Cooperative Medical Scheme implemented in 2003 in China, which aimed at reducing the rate of uninsured among the poor in rural areas. To address selection into the program the authors employ several different empirical methods, including fixed effects, instrumental variables, and difference-in-differences with propensity score matching. In general, their findings indicate that the scheme had limited success in accomplishing its goals. On the one hand, the authors show that participation in the program significantly decreased the use of traditional Chinese folk doctors and increased the utilization of preventive care, particularly general physical examinations. On the other hand, they do not find a reduction in out-of-pocket expenditures or an increase in the utilization of formal medical services. Importantly, their results do not show any improvements in health status. Bernal et al. (2014) examine the impact of Peru's "Seguro Integral de Salud," which provides insurance coverage to individuals employed outside the formal labor market, on healthcare use and health indicators. Using a fuzzy regression discontinuity design to address the program endogeneity, the authors

\footnotetext{
${ }^{9}$ They also examine the impact of the reform on supply-side responses and show that although the number of hospital beds went up, the number of medical institutions, physicians, and nurses did not seem to increase due to the reform.
} 
find that even though the reform had a positive impact on healthcare utilization and expenditures, it did not seem to have a significant effect on health outcomes. Chen et al. (2007) come up with similar conclusions in evaluating the effects of Taiwan's Health Insurance Reform of 1993 on access to healthcare and self-reported health status of the elderly. Specifically, they document that while access to health insurance increases utilization, it does not appear to lead to improved health.

While the evaluations of healthcare reforms emphasizing demand-side incentives produce a mixed picture, the evidence from investigations of reforms placing a greater focus on direct provision of medical care or creating financial incentives for healthcare providers is relatively more uniform. In particular, existing evidence supports the notion that increased availability of healthcare through direct provision or supply-side incentives improves health outcomes as well as access to healthcare services. One notable example is Thailand's 30 Baht Program (or Universal Coverage Scheme) of 2001, a large-scale supply-side intervention, which significantly increased payments to hospitals and decreased co-payments to increase access to medical care for the poor. Gruber et al. (2014) examine the impact of the 30 Baht Program employing a difference-in-differences estimator for identification, by comparing the outcomes of the previously uninsured and underinsured populations to those who had insurance coverage prior to the reform. The authors find that the reform led to increased healthcare utilization with more pronounced effects among the poor. Their estimates also show a significant decrease in infant mortality overall and a reduction in disparities in infant mortality across provinces.

Another well-known example of a supply-side reform is Brazil's Programa Saùde de Familia (PSF), launched in 1994 with the goal of expanding coverage of primary 
healthcare services to economically disadvantaged populations. As a community-based healthcare intervention, the PSF aims to provide basic health and preventive services through healthcare teams directly intervening at the community level. A few studies examine the effects of the PSF on health, controlling for municipal and/or state fixed effects and exploiting the gradual expansion of the program at the municipal level. For example, using state fixed effects to account for selectivity bias in expansion, Macinko et al. (2006) find that the PSF reduced the infant mortality rate. Similarly, Rocha and Soares (2010) examine the impact of the PSF on infant mortality, fertility, adult labor supply and school enrollment controlling for municipal fixed effects as well as state-by-year fixed effects. They find that the PSF reduced infant mortality, lowered fertility, increased labor supply of adults, and increased school enrollment in the North and Northeast regions of Brazil.

The findings from the Brazilian reform have the potential to provide insightful implications for the impact of the Turkish FMP given the similarities in the operational features between the two programs. The PSF is an initiative of the federal government, in which the delivery of primary healthcare is achieved through the deployment of professional healthcare teams at the community level (Rocha and Soares, 2010). This resembles the operations of family physicians in the FMP, who are responsible for providing basic healthcare services to the citizens assigned to them. Nevertheless, it is not straightforward whether the findings from the studies evaluating the Brazilian reform can necessarily be generalized to the Turkish case. This is because the participation for the PSF is voluntary at the municipality level and requires the coordination among all three layers of government at the federal, state, and municipal levels (Rocha and Soares, 2010), 
which may exacerbate the endogeneity of the program roll out. Furthermore, there is evidence to suggest that financial constraints at times caused a significant obstacle to the implementation of the PSF, which might again complicate identification (Noronha, 2010). One potentially satisfactory way to deal with these issues could be to adopt a more flexible functional form within the difference-in-differences strategy, for example, by relaxing the "parallel trends" assumption between the treated and control municipalities via municipality specific time trends. Rocha and Soares (2010) state that they could not implement this type of a sensitivity analysis due to the significant loss in the degrees of freedom, given that their data include a large number of municipalities. Instead, they allow for state-specific year dummies. ${ }^{10}$ In contrast to the PSF, the FMP is fully funded by general tax revenues and implemented by the central government with strong and unwavering commitment to operationalize the program in all provinces.

Although valuable lessons have been learned from the aforementioned analyses of supply-side healthcare reforms, the balance of the existing body of evidence remains tilted towards studies emphasizing insurance-based approaches. In this regard, the present analysis of the Turkish FMP will help towards accumulating evidence and perhaps emerging consensus on the importance of supply-side interventions. To our knowledge, the present paper constitutes the first analysis that focuses on evaluating the impacts of the FMP on birth and mortality outcomes. ${ }^{11}$

\footnotetext{
${ }^{10}$ Recently, Reis (2014) deals with these selection issues exploiting variation in the PSF's availability across siblings in order to account for unobserved family as well as municipality level factors that are constant over time. Unlike Rocha and Soares (2010), they find only weak evidence that the availability of the program at the municipality level is related to better health indicators of children in Brazil.

${ }^{11}$ We were able to identify only a preliminary version of a working paper by Aydemir and Guven (2015) who argue that the interaction term between the FMP and percent of women impacted by the compulsory schooling reform (CSR) of 1997 played a central role in determining the effectiveness of the FMP on child mortality. Note that this paper does not appear to be publicly available any longer, but we mention it here in the interest of full transparency. However, it is not clear what the interaction term between the FMP
} 


\section{The Family Medicine Program in Turkey}

The FMP was launched by the Ministry of Health of the Republic of Turkey, first as a pilot in the province of Düzce in 2005 and then gradually expanded to all 81 provinces by the end of 2010 (See Appendix Table 1 for a list of all provinces with their respective implementation dates). The program operates by assigning each citizen to a specific family physician, who offers a wide range of primary care services free-ofcharge. ${ }^{12}$ This is the key feature of the FMP and has been instrumental in the continuity of care as well as satisfaction and trust between the doctor and the patient (Baris et al., 2011; WHO, 2014b; Worldbank, 2012). In terms of governance, the Public Health Institution of Turkey (PHIT) is responsible for the oversight and broad management of the FMP. Moreover, in each province, the PHIT has a Public Healthcare Directorate responsible for operations at the local level. All family physicians are state-employed (OECD, 2014). Family physicians are paid on the basis of capitation adjusted by the socioeconomic development level of the region in which they work. Payments to family

indicator and the percent of women potentially impacted by the CSR captures. This is because the latter term is arguably correlated with numerous province characteristics not to mention that the CSR did not eliminate all the provincial differences in women's education, as vast differences in education across provinces exist even today. For example, the fraction of women impacted by the CSR may be greater in areas with higher baseline infant mortality levels. Another example would be that the fraction of women affected by the CSR might be greater in areas with lower levels of access to primary care prior to the implementation of the FMP. Consequently, there is no way to prove that the interaction term employed in their analysis corresponds to the convergence in child mortality due to the interplay between maternal education and primary care availability or convergence in child mortality because of the interaction between numerous other baseline province characteristics (e.g., initial child mortality levels and access to primary care) and the FMP. Furthermore, our results indicate that the FMP also lowered the adult mortality rate with more pronounced effects among the elderly. This finding contradicts with the view that the FMP operates through maternal education. In sum, their results have no clear interpretation, not to mention that there are other problems in their analysis (e.g., not taking into account age-specific population weights).

${ }^{12}$ Primary care services include preventive healthcare, examination, treatment and rehabilitation, maternity, maternal and infant health, outpatient or inpatient medical or surgical intervention and environmental health, forensic medicine and oral and dental health services. 
physicians are principally on a per capita basis and currently based on a catchment population of about 3,500 patients per doctor. ${ }^{13}$

The FMP services are delivered through two primary channels: Family Health Centers (FHCs) and Community Health Centers (CHCs). The FHCs staff family health teams formed by at least one family physician and an equal number of family health personnel including nurses and midwives. Basically, the FHCs are the clinics where patient-specific preventive care services (immunization and monitoring of pregnant women and infants) and diagnostic, curative, rehabilitative, and counseling services at the primary care level are provided. These centers serve as easily accessible walk-in clinics as they are located within the neighborhoods where assigned citizens reside and services can be obtained without having to make an appointment or to present any form of health insurance. The CHCs on the other hand are established to provide logistical support to family physicians for public health services such as vaccination campaigns and health promotion and education services, and environmental and occupational health services. Moreover, the CHCs collect statistical data on public health services, and monitor and evaluate the effectiveness of health services. Both the FHCs and CHCs are under the supervision of the Provincial Health Directorates that are responsible for planning and provision of health services at provincial level and accountable to the Public Health Institution of Turkey.

Prior to the FMP, the delivery of primary healthcare services had been managed through a highly hierarchical and fragmented system, which was difficult for patients to

${ }^{13} \mathrm{http}$ //ailehekimligi.gov.tr/sk-sorulan-sorular/personel-cin.html. 
understand and navigate through. ${ }^{14}$ Also, many patients had relied on hospitals to seek treatment for their health conditions. However, the proximity of these hospitals to patients presented an additional challenge in terms of access to basic services.

Furthermore, physician and laboratory services tend to cluster in neighborhoods adjacent to hospitals and this usually creates further obstacles in access to healthcare (Currie and Reagan, 2003).

The FMP has restructured the traditional public healthcare provision by shifting the administration and delivery of healthcare services from a centralized system to a model of decentralized healthcare governance. Through the FMP, essential and primary healthcare services are treated at the FHCs within the communities. For conditions that are more complicated or require specialists, patients are referred to hospitals. Therefore, the FMP may help to reduce the pressure and the waiting time for more serious and complicated conditions at the hospitals, which in turn, might improve health at a lower cost.

The FMP can influence the birth rates through the direct provision of contraceptive services, such as birth control pills and condoms, as well as changing women's fertility behavior via health counseling and education on reproductive health. Changes in mortality can be attributed to the fact that the FMP has dramatically improved

\footnotetext{
${ }^{14}$ For example, the Green Card-the "Yesil Kart"-program launched in 1992 was the main flagship social protection program that targeted the poor prior to the FMP. The Green Card program, a noncontributory health insurance scheme for the poor, covered only inpatient treatment costs of the eligible beneficiaries in public facilities until 2004. Under the Green Card Program, Turkish citizens living within the borders of the Republic of Turkey could be eligible if i) they were not covered by any social security schemes and ii) they have per capita household incomes of less than one-third of the gross minimum wage (except for taxes and social security premiums). Moreover, pensioners over 65 years old and people with chronic illnesses could be eligible, regardless of their household incomes (Worldbank, 2013a). The benefits of the program were expanded under FMP: outpatient services (in 2004) and prescription drugs (as of January 2005) in public facilities were included in the benefits package. In 2012, the Green Card program was integrated into the universal health insurance scheme (Worldbank, 2013a). The nationwide expansion of the benefits over time improved access to and utilization of healthcare services among the poor. This paper controls for common trends in order to identify the effect of the FMP.
} 
the quality of and the access to primary care in terms of preventive, curative, and rehabilitative services, especially for pregnant women, new mothers, infants, children, and the elderly, whose healthcare needs are the major focus of the FMP (WHO, 2012a; WHO, 2012b ). ${ }^{15}$ A detailed discussion of these mechanisms is provided in Appendix A.

\section{Data}

Indicators for the Family Medicine Program

Information on the FMP was obtained from the Public Health Institution of Turkey (PHIT). We construct a binary indicator for the presence of the FMP in a particular province in a given year. Next, we employ a continuous measure defined as the number of years since the implementation of the FMP in order to explore any dynamic patterns in the relationship between the program and the outcome measures. Finally, we allow for a fully non-parametric relationship by employing separate binary indicators for post-implementation years from 1 to 5 and more. In Appendix Table 1, we present the year of implementation of the FMP as well as the intensity of family physicians upon introduction of the FMP for each province. The PHIT aims to provide about 1 family physician for every 3,500 people living in a province. ${ }^{16}$ As it can be seen in Appendix Table 1 , this target rate (2.86 family physicians per 10,000 populations) has been achieved soon after the implementation of the FMP.

\footnotetext{
${ }^{15}$ Also see http://ailehekimligi.gov.tr/aile-hekimlii/aile-hekimliinin-tanm.html.

${ }^{16} \mathrm{http}$ ://ailehekimligi.gov.tr/sk-sorulan-sorular/personel-cin.html.
} 


\section{Outcome and Control Variables}

Data on birth and mortality rates come from the Turkish Statistical Institute (TurkStat). We consider multiple outcome categories by creating age-specific birth rate indicators, including Birth_rate ${ }_{\text {Age: } 15-19}$, Birth_rate ${ }_{\text {Age:20-24, Birth_rate }}$ Age:25-29, and Birth_rate 30-39. These age-specific birth rates reflect the number of births per 1,000 women in the associated age group.

Mortality rate measures are constructed in a similar fashion. All-age mortality rate $(A M R)$ represents the number of deaths per 1,000 people. Infant mortality rate (IMR) reflects the number of deaths among infants up to 12 months of age per 1,000 live births. Child mortality rate $(C M R)$ pertains to the number of deaths per 1,000 children between the ages 1 and 4 . Finally, elderly mortality rate $(E M R)$ represents the number of deaths per 1,000 people among those who are at least 60 years of age.

We account for a host of time-varying determinants of births and mortality in our econometric models. These covariates are measured either at the provincial or subregional level on an annual basis. ${ }^{17}$ The number of students per teacher in primary schools, the number of motor vehicles per 1,000 persons, and the share of governing party seats in the Turkish Parliament in the most recent general election $(2002,2007$, or 2011) are measured at the province level while the unemployment rate, and the percentage of population with at least a high school degree are measured at the sub-

\footnotetext{
${ }^{17}$ The TurkStat classifies Turkey into 12 regions and 26 sub-regions in addition to 81 provinces. These regional and sub-regional classifications are generated for statistical purposes based on geographic proximity and socio-economic similarities within the associated region. The TurkStat collects and processes data from different sources on a variety of topics including demographic characteristics and health. See http://www.turkstat.gov.tr for more information.
} 
regional level. ${ }^{18,19}$ Information on province populations as well as the age composition of population comes from the TurkStat. ${ }^{20}$

It is well-known that official statistics on mortality from developing countries, especially those on infant mortality, suffer from considerable measurement error (Anthopoulos and Becker, 2010; Cesur, Tekin, and Ulker, in press; Gruber et al., 2014). The measurement error is typically caused by factors such as difficulties in obtaining an accurate accounting of deaths due to religious and cultural practices observed in the burials of the dead and a large number of births delivered at non-hospital settings in developing countries. Therefore, the official statistics on mortality tend to underrepresent the actual number of deaths. Recognizing the measurement error in the official data, international organizations like the United Nations and the WHO adjust for the under-reporting by employing information from various sources such as official vital registries, census data, and demographic surveys (Gruber et al., 2014). This usually results in a discrepancy between the official mortality data released by national statistical agencies and international organizations.

In the present study, we can only use data obtained from the TurkStat because province level mortality statistics are not available from other sources. As demonstrated in Cesur, Tekin, and Ulker (in press) the trends in the national infant mortality rates obtained from the TurkStat data and the data from the United Nations and the WHO follow each other very closely. For example, the pairwise correlations in the infant

\footnotetext{
${ }^{18}$ Between 2001 and 2013, Turkey had three general elections (2002, 2007, and 2011), in which the members of the Grand National Assembly of Turkey were elected.

${ }^{19} \mathrm{We}$ also include binary indicators representing missing observations for each covariate.

${ }^{20}$ The information on province population and age composition from the TurkStat refer to the years 2000 and 2007-2013. Because no Census was administered in the period 2001-06, the associated province populations for these years are imputed using a linear growth rate.
} 
mortality rate between the TurkStat data and the series from the United Nations and the WHO are both 97 percent. The availability of FMP may cause a shift in the venues for deliveries from homes towards hospitals, which may then result in a decrease in infant mortality. This could still be interpreted as a program effect. At the same time, such a shift from home births towards hospital deliveries may improve the accuracy of accounting in the number of deaths. In this case, one may still obtain an effect on infant mortality even in the absence of any program impact because under-reporting would go down. It is important to note that such bias would go against finding a negative impact of the FMP on mortality, especially for infants. However, we control for province fixed effects and province-specific linear and quadratic time trends in our analysis as well as a set of time-variant province characteristics, which should help gauge any remaining heterogeneity that might threaten the reliability of our estimates.

Descriptive statistics on mortality and birth rates are presented in Table 1A and those on the control variables are shown in Table 1B. The birth rate among teenagers (i.e., ages 15-19) is 36.4 per 1,000, which goes up to 118.5 among women ages 20-24 and to 121.7 among women ages $25-29$, before going down to 63.2 among women ages 30 39. Note that these birth rate figures match well with other sources like OECD. ${ }^{21}$ Interestingly, the birth rates among the younger women (i.e., those ages 24 or less) are higher in the subsample without the FMP than the one with the FMP, but then the opposite is true among older women. This is consistent with the notion that the propensity to have the FMP in a province is positively associated with urbanization and industrial development.

\footnotetext{
${ }^{21}$ See OECD Family Sources Database www.oecd.org/social/family/database.
} 
Regarding mortality statistics, the rates are 10.6 and 0.6 per 1,000 for infants and children between ages $1-4$, respectively. The mortality rate for those age 60 and older is 28 per 1,000. A comparison between the subsamples with and without the FMP reveals that mortality rates are higher in the FMP provinces for all age categories. This pattern is also consistent with the notion that the provinces with the FMP program in effect are more urban and industrial than other provinces.

As shown in Table 1B, the time-variant province characteristics also vary considerably between sub-samples with and without the FMP. For example, the observations with the FMP appear to have a higher number of motor vehicles per capita, higher income and education, and smaller classrooms at schools. The pattern in these differences supports the view that the pace by which the FMP has expanded might have been positively associated with a higher level of urbanization and economic development. On the one hand, this may seem surprising given higher average incomes and better access to healthcare in more urban areas. On the other hand, there is evidence to indicate that health outcomes are negatively associated with living in urban areas, especially in developing countries, due to hazardous conditions such as stress and pollution (Health Effects Institute, 2010; McGranahan and Murray, 2003). Furthermore, these patterns are also consistent with high levels of income inequality in urban areas as well as the persistent trends in "urbanization of poverty" in the developing world (Ravallion et al., 2007). Additionally, in the context of Turkey, Cesur, Tekin, and Ulker (in press) show that air pollution is an important factor responsible for the higher infant mortality rates in urban provinces. In a recent working paper, the same authors document a similar pattern for the adult and the elderly mortality rates as well (Cesur, Tekin, and Ulker, 2015). 


\section{Econometric Framework}

Estimation of the causal impacts of the FMP on birth and mortality rates poses a difficult challenge because the roll out of the program is unlikely to be random with respect to outcome variables. Therefore, a comparison of outcomes between pre- and post-FMP periods is likely to produce biased estimates of the program effects. As shown in Tables 1A and 1B, there are differences in province characteristics and outcome variables by the FMP implementation status to support this notion. To further highlight the differences between provinces with and without the FMP, we regress time-varying province characteristics on a binary indicator variable for the presence of the FMP at the province level. The estimates from these regressions are presented in Table 2A. Note that each cell in this table corresponds to an estimate from a separate regression. As shown in column (1) of Table $2 \mathrm{~A}$, there is considerable variation between provinces with and without the FMP as they differ along all of the observable characteristics including unemployment rate, number of vehicles per capita, per capita income, percent of population with a high school degree, and number of students per teacher. The evidence from Table 2A suggests that having the FMP at the province level is positively associated with being more urban and economically developed. However, much of the differences in the propensity of having the FMP along with various province characteristics disappear once we control for just the time-varying differences across regions in column (2). However, it is when we control for the permanent differences across provinces through province fixed effects in column (3) that all of the observable differences between the two types of provinces become unrelated to the FMP. None of the estimates in column 
(3) are economically or statistically significant. This pattern remains preserved when we add province-specific linear and quadratic time trends in columns (4) and (5), respectively.

Next, we repeat the same exercise by replacing the binary treatment indicator with a continuous variable representing the number of years passed since the FMP implementation. The estimates from these regressions, which are displayed in Table 2B, point to the same conclusion that has emerged from Table 2A. Specifically, province characteristics are significantly and sizably related to the number of years that the program has been in place in a province, suggesting a more rapid adoption of the FMP in provinces that are more urban and economically developed than other provinces. But again, this pattern disappears once we control for fixed effects and trends.

To gain additional insights about the pattern in which the FMP has expanded across provinces and over time, we also estimate the binary FMP indicator and the number of years since the FMP implementation measures on jointly specified timevarying province characteristics. As shown in Appendix Tables 2A and 2B, province characteristics are initially significantly related to the FMP implementation even with all these characteristics entered into the model jointly. However, none of the estimates remain significant in both the statistical and the practical sense once we control for province fixed effects and province-specific trends.

Taken together, the evidence obtained from the descriptive analysis above is consistent with the assertion that the pattern of the roll out in the FMP implementation has been endogenous. Furthermore, it is also revealed that the factors that appear to be associated with the FMP have all become inconsequential once province fixed effects and 
province-specific time trends are accounted for. We interpret this as strong evidence that any remaining variation in the FMP measures considered above are plausibly exogenous to birth and mortality outcomes.

Although the program roll out does not appear to be random with respect to province characteristics, the FMP was introduced by the central government with the mandate to establish universal coverage eventually. Accordingly, the differences in the timing of implementation across provinces and over time primarily have to do with logistical and staffing considerations. In the end, all of the 81 provinces in Turkey had implemented the FMP during the analysis period. Therefore, there is no concern over selection bias that could be caused by certain provinces with a particular set of characteristics never getting the treatment. Furthermore, even if the implementation of the FMP appears to be non-random, any resulting bias could be eliminated by controlling for province fixed effects to the extent that the pattern of the roll out is only correlated with the pre-existing differences across provinces that are time-invariant (Rocha and Soares, 2010).

However, it is possible that some of the differences across provinces that are responsible for the non-random pattern of the FMP roll out are in fact dynamic. For example, provinces with particularly poor health conditions might have not only received priority for the FMP, but they might have also enjoyed a series of other investments by the central government. Consequently, health conditions in these provinces might have improved more rapidly than they did for other provinces. In order to account for the possibility of dynamic evolution in the outcomes of birth and mortality rates, we also control for province-specific linear as well as quadratic time trends in our empirical 
analysis. Finally, we account for a range of time-variant province characteristics that capture some of the factors that may be associated with the implementation of the FMP as discussed above. These province level characteristics include unemployment rate, income per capita, number of motor vehicles per capita, percentage of province population with a high school degree, number of students per teacher, and the province's share of the parliament members affiliated with the political party governing Turkey.

After accounting for these differences across provinces, our approach to obtaining the causal impact of the FMP on birth and mortality outcomes is to implement a difference-in-differences estimation strategy, taking advantage of the fact that the program was rolled out in a staggered basis across provinces over time. In doing so, we compare the difference in the outcome variables in provinces before and after the FMP implementation net of those provinces without the FMP in place. The empirical model implementing the difference-in-differences estimation strategy can be expressed by the following equation:

$$
\mathrm{Y}_{\mathrm{pt}}=\beta_{0}+\mathrm{X}_{\mathrm{pt}} \beta_{1}+\beta_{2} \mathrm{FMP}_{\mathrm{pt}}+\delta_{\mathrm{rt}}+\lambda_{\mathrm{p}}+\varphi_{\mathrm{p}} \mathrm{t}+\varphi_{\mathrm{p}} \mathrm{t}^{2}+\varepsilon_{\mathrm{pt}}
$$

where $Y_{p t}$ is the logarithm of one of our outcome variables measured in province $p$ in year $t$. The vector $\mathrm{X}_{\mathrm{pt}}$ represents the time-varying province level characteristics. $\mathrm{FMP}_{\mathrm{pt}}$ is a binary variable indicating the presence of the family medicine program in place. The $\delta_{\mathrm{rt}}$ is a set of region-by-year fixed effects included in the model in an attempt to control for common trends and shocks to health outcomes that might be correlated with health investments including the FMP at the regional level. The region-by-year fixed effects 
would also account for time trends that are common across all provinces. Accounting for such trends is important because there had been a number of other health-related initiatives implemented during our analysis period, such as the introduction of additional services including neonatal care, free birth delivery, and mobile pharmacy and helicopterbased emergency medical services to improve access in rural areas. However, these policies became effective concurrently nationwide and therefore their effects should be captured by year fixed effects. Regions in Turkey are clusters of provinces grouped together based on considerations of geographical proximity to each other and statistical purposes. ${ }^{22}$ The inclusion of region-by-year fixed effects would also account for the possibility of potential spillover effects of the FMP to neighboring provinces as well as potential correlation in the timing of adoption of the FMP across provinces within a region due to cost savings associated with operational efficiency. The $\lambda_{\mathrm{p}}$ represents province fixed effects accounting for permanent differences across provinces such as poverty as well as cultural and traditional practices, which likely remained time-invariant during the analysis period.

The difference-in-differences evaluation method requires the parallel trends assumption, i.e., the outcome variables would have been trended in a parallel pattern between the FMP and non-FMP provinces in the absence of the FMP implementation. Although the parallel trends assumption is not directly testable, valuable insights can be gained by conducting an event study analysis, which would allow us to trace out the trends in the outcome variables year-by-year leading up to and following the

\footnotetext{
${ }^{22}$ There are 12 statistical regions in Turkey. As the province of Istanbul constitutes a region itself, it is merged with the neighboring West Marmara region for computational simplicity when we constructed the region-by-year fixed effects. However, treating Istanbul as a separate region or dropping it from the sample produces nearly identical results.
} 
implementation of the FMP. Formally, this can be done by estimating regressions for each outcome variable on a set of five binary indicators representing the years leading up to and following the implementation of the FMP. Estimates from this analysis are plotted along with their 95 percent confidence intervals in Figure 1A for birth rates and in Figure 1B for mortality rates. As illustrated in these figures, there is a clear overall pattern of a divergence in the outcome variables from their pre-FMP period trends following the implementation year. For the birth rates shown in Figure 1A, the pattern of divergence is strongest for women in the first three age categories. For women ages 30-39, there is a reversal in the birth rate associated with the FMP implementation, though none of the estimates are statistically significant at the 95 percent level. For the mortality rates shown in Figure 1B, the pattern is clearly strong and visible for all age categories. ${ }^{23}$ Therefore, the event study analysis is largely supportive of the parallel trends assumption, suggesting no systematic evidence that our results would reflect the continuation of any long-run pre-existing trends in the outcome variables. Nonetheless, the specification in equation (1) still relaxes the parallel trends assumption by allowing for trends in mortality and fertility rates to differ across provinces by accounting for province-specific linear and quadratic trends. These trends, denoted by the terms, $\varphi_{p} t$ and $\varphi_{p} t^{2}$, would capture the influence of difficult-to-measure factors at the province level that trend either linearly or quadratically over time. The parameter of interest in equation (1) is $\beta_{2}$, which represents the average change in the outcome of interest after the implementation of the FMP net of any change in the outcome variable in control provinces. Finally, $\varepsilon_{\mathrm{pt}}$ is an idiosyncratic error term.

\footnotetext{
${ }^{23}$ It is expected that the confidence intervals get wider as we move further away from the implementation year because of reduced variation due to smaller number of provinces in these categories. Nevertheless, it is remarkably clear that there is a reversal in the trends caused by the FMP.
} 
The empirical model specified in equation (1) assumes that the impact of FMP on the rates of birth and mortality is homogenous in the sense that the birth and mortality responses to the FMP are constant across years. However, this may not be true for several reasons. For example, the health benefits of the program may be the largest early in the post-implementation period because large populations, who did not previously have access to basic healthcare, gain access to a wide range of services all of a sudden. Alternatively, it may take some time for the widespread adoption of the program since many individuals may not be aware of the program in the beginning or may be reluctant to switch from the existing practices early on. Accordingly, the program effects may be felt gradually over an extended period of time. The results from the models described above would reflect the program effects averaged over the number of years since its implementation. Therefore, these results may mask important differences in the dynamics regarding the evolution of the program impacts if the underlying relationship between the FMP and outcomes in consideration is not constant over time. To test this, we modify equation (1) in two ways to allow for a more flexible relationship between the FMP and the outcome measures. First, we replace the binary treatment variable with a continuous measure defined as the number of years since the implementation of the FMP:

$$
\mathrm{Y}_{\mathrm{pt}}=\beta_{0}+\mathrm{X}_{\mathrm{pt}} \beta_{1}+\beta_{2} \text { Years_since_FMP } \mathrm{FMt}_{\mathrm{pt}}+\delta_{\mathrm{rt}}+\lambda_{\mathrm{p}}+\varphi_{\mathrm{p}} \mathrm{t}+\varphi_{\mathrm{p}} \mathrm{t}^{2}+\varepsilon_{\mathrm{pt}}
$$

Second, we consider a fully flexible non-parametric specification in which we use separate dummy variables for various years since the implementation of the FMP: 


$$
\mathrm{Y}_{\mathrm{pt}}=\beta_{0}+\mathrm{X}_{\mathrm{pt}} \beta_{1}+\sum_{\mathrm{k}=1}^{5+} \beta_{\mathrm{k}} \mathrm{k}_{-} \text {years_since_FMP } \mathrm{F}+\delta_{\mathrm{rt}}+\lambda_{\mathrm{p}}+\varphi_{\mathrm{p}} \mathrm{t}+\varphi_{\mathrm{p}} \mathrm{t}^{2}+\varepsilon_{\mathrm{pt}}
$$

We estimate all of our models using weighted regressions in which province population for the relevant age category is used as a weight. Finally, in all analyses, standard errors are robust to clustering at the province level, making statistical inference robust to arbitrary forms of both heteroskedasticity and serial correlation within provinces over time (Bertrand et al., 2004).

\section{Results}

The Impact of the FMP on Age-Specific Birth Rates

The estimates on the impact of the FMP on the logarithm of birth rate from the model specified in equation (1) are presented in Table 3. We report estimates in separate columns for women in four different age categories including those ages 15-19, 20-24, 25-29, and 30-39. Furthermore, the estimates are shown in four separate panels, each of which successively includes an additional set of control variables. Specifically, Panel A shows the estimates from a specification that only controls for region by year fixed effects. Province fixed effects are added to this specification in Panel B and provincespecific linear and quadratic time trends are controlled for in Panel C. Finally, a vector of time varying province characteristics is included in the specification in Panel D.

As shown in the first column of Panel A, the FMP is associated with a decrease in birth rates among all age groups, though the estimates are statistically significant only for teenagers and younger women in ages 20-24. According to point estimates, the FMP is

associated with a 19.2 percent $\left(\mathrm{e}^{-0.213}-1=-0.192\right)$ decrease in the birth rate among 
teenagers and a 13.2 percent $\left(\mathrm{e}^{-0.141}-1=-0.132\right)$ decrease in the birth rate among women ages 20-24. As argued earlier, these estimates may partially account for the differences in province characteristics that are correlated with both the timing of the FMP as well as birth outcomes. For instance, the timing of FMP appears to be positively correlated with province characteristics that reflect a higher level of urbanization, educational attainment, and industrial development. To the extent that these characteristics are negatively correlated with fertility, the estimates that fail to account for them would be biased upwards. In an attempt to account for these confounding factors, we present estimates from a specification that controls for province fixed effects in Panel B. As expected, the magnitudes of the estimates are reduced dramatically in response to controlling for permanent differences across provinces. In fact, the FMP now appears to have an effect only on the birth rate of teenagers. The estimates change little when we further control for the linear and quadratic trends in Panel $\mathrm{C}$ and time-variant province characteristics in Panel D. Focusing on Panel D, the estimates are arguably zero both economically and statistically for all age categories except for teenagers. According to the point estimates, the birth rate among teenagers is reduced by 3 percent $\left(\mathrm{e}^{-0.03}-1=-0.03\right)$ in response to the FMP. Taking the average birth rate among women ages 15-19 for non-FMP observations as a base, this estimate translates into about 1.19 fewer births per 1,000 women in this age group. With an average population of 39,659 women between ages $15-19$, this is equivalent to an effect size of 47.2 births per province.

The finding of a negative impact of the FMP on the birth rate of teenagers may be due to increased access to reproductive health services and increased counseling and education regarding birth control methods provided by family physicians. Furthermore, 
teenagers are likely to be the age group who might benefit from these services the most. At around 3.5 percent of the female adolescent population, Turkey has the highest teenage birth rate following Mexico and Chile among the OECD countries, for which data are available in 2011 (OECD Family Database, 2015). Teenage pregnancy has been linked to adverse outcomes for both mothers and children in a variety of domains, including education, labor market, and health (Güneş, 2014; Hoffman, 2006; Hoffman and Maynard, 2008; Klepinger et al., 1999; Martin et al., 2011; Ribar, 1994; Walker et al., 2009).${ }^{24}$ Therefore, the finding of a negative impact of the FMP on teenage birth rate suggests that the benefits of the program may extend well beyond the improved health and include positive spillovers in economic and social contexts, which may support women's reproductive decisions and ultimately improve their status in the society.

Next we present results from the estimation of the models specified in equations (2) and (3), in which we allow the FMP impact to vary flexibly over time. As shown in the top panel of Table 4, there appears to be a negative relationship between the FMP and all four age-specific birth rates that is decreasing over time. The estimates are statistically significant for all women except for those between ages 20-24. This indicates a specification that restricts the FMP impact to be the same across years in postimplementation period would mask important differences in the patterns concerning the program dynamics. These differences become even clearer when we employ a fully nonparametric specification in Panel B. For example, focusing on the birth rate among teenagers, the FMP impact sets in rather immediately with an estimate of 2.4 percent, and increases to around 5 percent in the second year and then remains stable around that level

\footnotetext{
${ }^{24}$ Accordingly, reducing teenage fertility has been identified as one of the Millennium Development Goals by the United Nations.
} 
thereafter. The lack of precision for the last two indicators is likely caused by reduced variation due to relatively fewer number of province-year observations with the FMP in place for four years or more.

Interestingly, the FMP is unrelated to the birth rate among women ages 20-24. Consistent with the top panel, all of the estimates are insignificant both economically and statistically for this group. As illustrated in Table 1A, this is an active child-bearing age for women in Turkey, which is not surprising given the relatively low age at marriage. ${ }^{25}$ Then, if these women are more likely to become first-time mothers, then they might be less interested in obtaining family planning services. In other words, there is no particularly strong role for the FMP to influence the fertility decisions of these women. Therefore, the lack of statistical and economic significance for this age group is not surprising.

Turning to the estimates for women ages 25-29 and 30-39, the emerging picture is that the FMP has an impact that is increasing in its intensity over time. In fact, the estimates are small and insignificant for the first two years and then pick up for years three and four. The estimates on the indicator for five years or more since the program implementation are imprecisely estimated, again likely due to the small number of provinces with the program in place for at least five years.

It is important to note that every single estimate in Table 4 is negative although there are some differences across age groups in the extent to which these estimates are statistically significant. The immediate reduction observed for the birth rate among teenagers may be explained by expanded access to birth control as well as counseling and

\footnotetext{
${ }^{25}$ According to the TurkStat, the average age at first marriage for women was slightly under 23 until 2009 and has been around 23 since then. See http://www.tuik.gov.tr/Kitap.do?metod=KitapDetay\&KT ID=11\&KITAP ID=18 for more detail.
} 
education in reproductive health that might have led to increased awareness about the negative consequences of teenage pregnancy. Simply the increased contact between teenagers and family physicians might have given way to reduced teenage fertility through changes in behavior. There is also evidence to suggest that the FMP has allowed healthcare personnel to fight more effectively in their efforts to curb teenage pregnancy. ${ }^{26}$ If reducing teenage pregnancy had been indeed viewed as a priority goal, then this may also explain the finding that the FMP effect sets in rather immediately for this age group. In contrast, reducing birth rate among women at prime childbearing ages is not a stated program goal. ${ }^{27}$ Therefore, any reduction in the birth rates among women in older age categories might be attributable to increased education about reproductive health and access to modern contraceptives services made possible by the program. ${ }^{28}$ Furthermore, one might expect these women to have a higher propensity to find out about birth control methods since they are more likely to have had a child earlier. Therefore, it makes sense for the impact for these women to set in gradually over time rather than immediately. Finally, the FMP could have improved the overall health among women in general, which might have then led to increased labor market productivity and participation. If this is the case, then women might have shifted their fertility preferences towards having fewer children due to increased opportunity cost of time (Becker, 1981; Schultz, 1981).

\footnotetext{
${ }^{26}$ See http://www.ergensagligi.org.tr/pdf/KongreBildiriKitabi3.pdf.

${ }^{27}$ On the contrary, in many occasions during the analysis period, President of Turkey, Recep Tayyip Erdogan, has publicly urged Turkish women to have at least three children and described birth control as a threat to country's lineage. He has also repeatedly blamed birth control advocates for hindering the country's efforts to grow (Yeginsu, 2014).

${ }^{28}$ One exception may be women over age 35 , who are considered to be in the risky category in terms of facing complications during pregnancy. Both the program guidelines and our conversations with family physicians suggest that a high priority is given to risky pregnancies, which is defined as pregnancies among women younger than 18 or older than 35, in less than two-year intervals, and more than four pregnancies in total.
} 
Finally, we examine whether the impact of the FMP on the birth rates depends on baseline birth rates measured prior to the FMP implementation. ${ }^{29}$ This would reveal any efforts taken on the part of the FMP administrators including family physicians to prioritize efforts based on initial birth rates. For example, it is plausible to imagine that efforts might have been concentrated on reducing teenage birth rate among provinces with a particularly high teenage pregnancy rate. If that is the case, then the FMP might have also contributed to an equalization of teenage birth rates across provinces. To investigate this, we estimate our most comprehensive specification with the FMP indicator and an interaction term between the FMP and the birth rate for the relevant age group in the average of three-years prior to the FMP implementation. As shown in Appendix Table 3, this analysis produces no evidence to support the story described above. With the exception of the birth rate among teenagers, the estimates on the FMP and the interaction term are not statistically significant. For the teenage birth rate, the FMP and its interaction with the baseline teenage birth rate are jointly significant at the five percent level. The point estimate for the FMP is negative as expected, suggesting that the FMP is associated with a decline in birth rate among teenagers. However, the interaction term is practically zero, which suggests no evidence to indicate that such strategic action to target provinces with a high rate of teenage pregnancy had taken place.

\section{The Impact of the FMP on Age-Specific Mortality Rates}

We begin presenting the estimates on the impact of the FMP on the logarithm of mortality rates with Table 5. Similar to the results for the birth rates, we report the

\footnotetext{
${ }^{29}$ In calculating the baseline birth rates, we averaged the birth rates in the associated age group in the three years before the adoption of the FMP. Using the average birth rates for all the available years preceding the implementation of the FMP produced quantitatively and qualitatively similar estimates.
} 
mortality estimates for various age categories arrayed in columns (1) through (4) including all-age mortality rate (AMR), infant mortality rate (IMR), mortality rate for children under age 5 (CMR), and mortality rate among the elderly (age 60 and older) (EMR).

The Panel A of Table 5, in which we only control for region-by-year fixed effects, indicates a positive association between the FMP and mortality rates for all age categories, although only the estimates on all-age and infant mortality rates are statistically significant. This seemingly counterintuitive pattern highlights the importance of addressing the endogeneity of the FMP. In fact, this pattern is already illustrated in Table 1A, which shows that the mean mortality rates are higher in the FMP sub-sample than the non-FMP subsample for all age groups. Furthermore, as we have shown earlier, the presence of the FMP is positively associated with province characteristics that reflect a higher level of urbanization and industrialization. Therefore, it is not surprising to see a higher rate of mortality in provinces with the FMP in a specification that fails to capture the impact of these characteristics properly. As expected, the contradictory pattern obtained in Panel A disappears and all the estimates become negatively signed in Panel B once we control for province fixed effects. Furthermore, the estimates are statistically significant with the exception of the rate of mortality among children ages $1-4$. The estimates are attenuated slightly after accounting for unobserved heterogeneity by controlling for province-specific linear and quadratic trends, and then time-varying characteristics of provinces in Panels C and D. According to the point estimates in Panel $\mathrm{D}$, the FMP is associated with a 5.6 percent $\left(\mathrm{e}^{0.058}-1=-0.056\right)$ decrease in the overall mortality rate. With a mean mortality rate of 2.88 per 1,000 persons for the sub-sample 
with $\mathrm{FMP}=0$, this estimate implies that the FMP reduced mortality by about 0.16 per 1,000 persons. Turning to age-specific mortality estimates, the impact of the FMP on infant mortality is 14.2 percent $\left(\mathrm{e}^{-0153}-1=-0.142\right)$, while the effect on the elderly mortality rate is 5.2 percent $\left(\mathrm{e}^{-0.053}-1=-0.052\right)$. With the sample mean of infant mortality rate of 10.04 per 1,000 infants, the marginal effect of negative 14.2 percent translates into a reduction of 1.43 infant deaths per 1,000. Similarly, with a mean mortality rate of 20.44 per 1,000 among the elderly, the reduction in deaths among this group would be 1.06 per 1,000 persons.

The effect on the mortality rate of children ages 1-4 is not estimated with precision. One possible explanation for this finding may be that the baseline mortality rate is much lower among children ages 1-4 in the first place. But it may also be due to the restrictive nature of the binary treatment model, which constraints the FMP impact to be identical across years.

To shed light into the dynamic nature of the relationship between the FMP and mortality rates, we turn to results from the estimation of the models specified in equations (2) and (3). As shown in the top panel of Table 6, the impact of FMP on the mortality rate is statistically significant, negative and in absolute term increases over time for all of the four age categories. Contrary to the previous table, the impact of the FMP on the mortality rate among children ages 1-4 is statistically significant and a linearly decreasing function of the number of years since the FMP implementation. Each additional year of the FMP implementation reduces the mortality rate among infants by 23 percent $\left(\mathrm{e}^{-0.26}\right.$ $1=-0.23)$, among children ages $1-4$ by 25 percent $\left(e^{-0.282}-1=-0.25\right)$ and among the elderly by 7.8 percent $\left(\mathrm{e}^{-0.082}-1=-0.078\right)$. The overall reduction in the all-age mortality rate is 10 
percent $\left(\mathrm{e}^{-0.106}-1=-0.10\right)$. Note that although the largest estimate is for the mortality rate among children ages 1-4, the actual lives saved by the FMP is the lowest among this group of children given that the baseline mortality is the smallest for them. For example, in the first year of the FMP, about 0.133 children per 1,000 between ages 1-4 are saved by the program. This is in contrast to 2.309 and 1.595 lives per 1,000 among infants and the elderly, respectively. The dynamic nature of the relationship between the FMP and the mortality rate is seen more clearly in the bottom panel of Table 6 , in which we specify a fully nonparametric model. The estimates indicate a strong and negative relationship between the FMP and mortality for all age groups. Furthermore, the effect appears to be persistent and accumulating over time. Considering the fact that the mortality rates are much higher for infants and the elderly than children ages 1-4, the effect sizes are again much larger for these two groups than children ages 1-4 as well, despite large estimates for children.

Finally, we present results from a specification in which we control for the FMP along with its interaction with the mortality rate of the relevant group in the 3 years prior to the FMP. ${ }^{30}$ This rather descriptive exercise allows us to test whether the implementation of the FMP induces the mortality rates between provinces with high and low initial mortality rates to converge. ${ }^{31}$ As shown in Appendix Table 4, all of the estimates are highly significant both individually and jointly. Furthermore, the estimates on the FMP indicator are uniformly positive while the estimates on the interaction terms are all negative. However, when calculated at the means, the effects are all negative,

\footnotetext{
${ }^{30}$ Averaging the mortality rates in all the years prior to the implementation of the FMP for the calculation of the baseline mortality rates leads to nearly identical estimates.

${ }^{31}$ It would have been highly informative if a similar exercise were to be undertaken based on using the initial primary care access and utilization levels. Unfortunately, because the province level primary care access and utilization data are not available, we are not able to undertake this robustness check.
} 
which is consistent with the notion that the FMP had a negative impact on the mortality rates. The negative sign in the interaction term indicates that the program has been more effective in reducing mortality in provinces with higher initial mortality rates. It may be due to the possibility that provinces with worse initial health conditions will experience a steeper decrease in mortality since even a low dose of increase in the quality of and access to healthcare would have a meaningful impact on mortality. Another explanation might be that program staff works more intensively in their efforts to reduce mortality in provinces with a particularly acute mortality problems. Regardless, the estimates presented in Appendix Table 4 provide evidence in favor of the view that increased primary care availability may help reduce geographical disparities in mortality rates across provinces. This result is consistent with Gruber et al. (2014) who found a similar pattern of provincial convergence in their evaluation of the impact of a supply-side reform on infant mortality in Thailand.

\section{Conclusions}

Over the past decade, the Turkish healthcare system has undergone a major transformation marked by significant investments in infrastructure, education of healthcare personnel, modernization of patient tracking and payment systems, and most importantly, the launching of the Family Medicine Program (FMP). With the introduction of the FMP in 2005, Turkey has essentially established a socialized healthcare system for primary healthcare services, under which every Turkish citizen is ensured a comprehensive package of healthcare service that is free-of-charge irrespective of the citizen's ability to pay. This paper provides the first comprehensive analysis of the impact 
of the FMP on the outcomes of age-specific birth and mortality rates using province level data between 2001 and 2013. To identify the causal effect of the FMP, we exploit the variation in program implementation across provinces and over time using a differencein-differences estimation strategy. Our results indicate that the FMP has caused reductions in both mortality and birth rates. The benefits associated with the FMP appear to be the strongest among the most vulnerable populations, i.e., the infants and the elderly for the mortality rate, and the teenagers for the birth rate. Furthermore, the results indicate that the program resulted in a more rapid reduction in mortality in provinces with a higher baseline mortality rate. This implies that the FMP might have also contributed towards an equalization of the mortality disparities across provinces.

Supply-side approaches to addressing the problem of underutilization and access to healthcare are a subject of increasing interest to governments and international health organizations (United Nations Sustainable Development Solutions Network, 2014; WHO, 2014a). However, rigorous and large-scale evaluations of these types of interventions are rare because most nationwide reforms concern demand-side incentives such as expanding health insurance to poor populations. Meanwhile, a handful of recent studies highlight the importance of supply-side reforms in improving public health and reducing disparities in health outcomes in countries like Brazil and Thailand. The current study builds upon this growing strand of literature by documenting evidence on the effectiveness of a nationwide supply-side intervention from Turkey, which emphasizes direct service provision and effective government oversight. The findings in this paper provide further compelling evidence in favor of the view that extending healthcare services to all citizens is critical to achieving universal coverage and improving public health. 
The signature feature of the Turkish FMP is the assignment of every citizen to a new category of "family physicians," who are the central and first point of contact for patients. Every Turkish citizen is required to register with a particular family physician, who is in charge of providing a wide range of healthcare services at neighborhood clinics that operate on a walk-in basis. Family physicians are reimbursed primarily via a prorated capitation payment, adjusted for local health needs, calculated on the basis of local pregnancy rates, elderly population, prison population and development index (OECD, 2014). These per capita payments are based on a catchment population of about 3,500 patients per family physician. The Turkish Ministry of Health is targeting to reduce this ratio to 2,000 by 2023 . Since family physicians play a critical role for the success of the FMP, a relevant question to consider is the marginal productivity of each family physician in terms of reducing birth and mortality rates. A rough back of the envelope calculation can be made by dividing the changes in outcome variables by the average number of family physicians per province, which is 239 per province during our analysis period. For example, according to our estimates, the impact of FMP in its first year of implementation on teenage birth rate is a 2.4 percent, which would translate into 0.95 fewer births per 1,000 women between ages 15-19. Given that there are roughly 39,600 teenagers per province, the FMP would reduce the number of births among these women by around 38 per province in the first year. If we assume that all of the FMP impact is attributable to family physicians, the marginal productivity of a doctor in reducing teenage birth rate would be about $0.16(47 / 239)$ teenage births. Similarly, the first year impact of the FMP on infant mortality is 15.8 percent. Given the average infant mortality of 10.04 for the sub-sample $\mathrm{FMP}=0$, this would be equivalent to 1.59 lives saved among 
1,000 infants per province. Then the number of infant lives saved per province is about 25 annually, which would imply that the marginal productivity of a family physician in saving the live of an infant is 0.10 . Similarly, the number of the elderly persons saved per province is about 95 annually, which would imply that the marginal productivity of a family physician for saving the live of an elderly person is about 0.40 . 


\section{References}

Anthopolos, R. and Becker, C.M. (2010). Global infant mortality: Correcting for undercounting. World Development, vol. 38(4), pp. 467-81.

Aquino,R., de Oliveira N.F., and Barreto M. (2009). Impact of the family health program on infant mortality in Brazilian municipalities. American Journal of Public Health, 99(1):87-93.

Arroyave Ivan, Doris Cardona, Alex Burdorf, and Mauricio Avendano (2013). The impact of increasing health insurance coverage on disparities in mortality: Healthcare reform in Colombia, 1998-2007. American Journal of Public Health, Vol. 103, No. 3, pp. e100-e106.

Aydemir, A., and C. Güven (2015). The effects of primary care and parental education on infant mortality: Evidence from concurrent natural experiments of family medicine implementation and compulsory schooling reforms in Turkey. Working Paper.

Bailey, Martha J., and Andrew Goodman-Bacon (2015). The War on Poverty's Experiment in Public Medicine: Community Health Centers and the Mortality of Older Americans. American Economic Review, 105(3): 1067-1104.

Baris, E., S. Mollahaliloglu and S. Aydin (2011). Healthcare in Turkey: From Laggard to Leader. British Medical Journal, Vol. 342, p. c7456.

Becker, G. S. (1981). Treatise On the Family. Harvard University Press, Cambridge, MA.

Bernal, N., Carpio, M. A., and Klein, T. J. (2014). The effects of access to health insurance for informally employed individuals in Peru. IZA Discussion Paper No. 8213.

Bertrand, Marianne, Esther Duflo, and Sendhil Mullainathan (2004). How Much Can We Trust Differences in Differences Estimates? Quarterly Journal of Economics, 119:1, 249-275.

Bitrán, Ricardo, Rodrigo Muñóz, and Lorena Prieto (2010). Health insurance and access to health services, health services use, and health status in Peru. Escobar/Griffin/Shaw: 106.

Camacho, A., and Conover, E. (2013). Effects of subsidized health insurance on newborn health in a developing country. Economic Development and Cultural Change, 61(3): 633658.

Carrin, G., Aviva R., Yang H. et al. (1999). The reform of the rural cooperative medical system in the People's Republic of China: Interim experience in 14 pilot counties. Social Science and Medicine, 48(7):961-972. 
Cercone, James, Etoile Pinder, Jose Pacheco Jimenez, and Rodrigo Briceno. (2010).

Impact of health insurance on access, use, and health status in Costa

Rica."Escobar/Griffin/Shaw: 89.

Cesur, Resul, Erdal Tekin, and Aydogan Ulker. (2015) " Residential Heating Practices and Adult Health: Quasi-experimental Evidence from the Rollout of Natural Gas Infrastructure" Working Paper.

Cesur, Resul, Erdal Tekin, and Aydogan Ulker. (In press) "Air pollution and infant mortality: evidence from the expansion of natural gas infrastructure." The Economic Journal .

Chen, Likwang, Winnie Yip, Ming-Cheng Chang, Hui-Sheng Lin, Shyh-Dye Lee, YaLing Chiu, and Yu-Hsuan Lin. (2007). The effects of Taiwan's national health insurance on access and health status of the elderly. Health economics 16, no. 3: 223-242.

Cheng SH, Chiang TL. (1997). The effect of universal health insurance on healthcare utilization in Taiwan. JAMA, 278(2):89-93.

Currie, Janet, and Patricia B. Reagan (2003). Distance to hospital and children's use of preventive care: is being closer better, and for whom? Economic Inquiry, 41, no. 3 (2003): 378-391.

Demirel, Gamze, Basak Tezel, Sema Ozbas, Serife Suna Oguz, Omer Erdeve, Nurdan Uras, and Ugur Dilmen. (2013). Rapid decrease of neonatal mortality in Turkey. Maternal and child health journal, 17 no. 7: 1215-1221.

Dow, W. H., and Schmeer K.K. (2003). Health insurance and child mortality in Costa Rica. Social Science and Medicine, 57:975-986.

Ekman, B., Liem N.T., Duc H.A., and Axelson, H. (2008). Health insurance reform in Vietnam: A review of recent developments and future challenges. Health Policy and Planning, 23(4):252-263.

Giedion, U. and Diaz, B. Y. (2010). A review of the evidence. In M.-L.Escober, C. C. Griffin, and P. R. Shaw (Eds.), The impact of health insurance in low- and middleincome countries (pp. 13-32). Washington, DC: Brookings Institution Press.

Goldman, L. and E. Francis Cook. (1984). The decline in ischemic heart disease mortality rates. An analysis of the comparative effects of medical interventions and changes in lifestyle. Annals of Internal Medicine, 101(6):825-836.

Gruber, J., Hendren N., and Towsend R. M. (2014). The great equalizer: Health care access and infant mortality in Thailand. American Economic Journal: Applied Economics, 6(1):91-107. 
Güneş, P.M. (2014). Essays on female education, fertility, and health: Evidence from Turkey and the US (Doctoral dissertation).

Health Effects Institute (2010). Outdoor air pollution and health in the developing countries of Asia: A comprehensive review. Special Report 18, Boston, Massachusetts.

Hoffman, Saul D. (2006). By The Numbers: The Public Costs of Teen Childbearing. Washington, DC: National Campaign to Prevent Teen and Unplanned Pregnancy.

Hoffman, Saul D., and Rebecca A. Maynard, eds. (2008). Kids Having Kids: Economic Costs and Social Consequences of Teen Pregnancy, 2nd edition. Washington, DC: The Urban Institute Press.

Klepinger D, Lundberg S, Plotnick R. (1999). How does adolescent fertility affect the human capital and wages of young women? Journal of Human Resources, 34:421-448.

Kondo, A., and Hitoshi S. (2013). Effects of universal health insurance on health care utilization, and supply-side responses: evidence from Japan. Journal of Public Economics, 99 (2013): 1-23.

Kruk, M.E., Porignon D., Rockers P. C., and Lerberghe W.V. (2010). The contribution of primary care to health and health systems in low- and middle-income countries: A critical review of major primary care initiatives. Social Science and Medicine, 70:904-911.

Lei, X., and Lin, W. (2009). The new cooperative medical scheme in rural China: Does more coverage mean more service and better health? Health Economics, 18(2), S25

Levene, L.S., Baker, R., Bankart, M.J.G., and Khunti, K. (2010). Association of features of primary health care with coronary heart disease mortality. Journal of American Medical Association, 304:2028-34.

Macinko, J., Guanais F., and Souza M. (2006). Evaluation of the impact of the family health program on infant mortality in Brazil, 1990-2002. Journal of Epidemiology and Community Health, 60(1):13-19.

Martin, Joyce A., et al. (2011). "Births: Final Data for 2009.” National Vital Statistics Reports, 57(7). Hyattsville, MD: National Center for Health Statistics.

McGranahan, G. and Murray, F. (2003). Air pollution and health in rapidly developing countries. Earthscan Publications Ltd, London, UK.

Nicholson, D. R. Yates, W. Warburton, G. Fontana. (2015). Delivering Universal Health Coverage: A Guide for Policymakers. Report of the WISH Universal Health Coverage Forum. World Innovation Summit for Healthcare, Qatar. 
Nolte, E. and M. McKee (2004). Does healthcare save lives? Avoidable mortality revisited. The Nuffield Trust, London.

Noronha, J. (2010). Brazil's march towards universal coverage. Bull World Health Organ, 88, 646-647.

OECD (2014). OECD Reviews of Health Care Quality: Turkey 2014 Raising Standards.

OECD Family Database (2015). Share of Births Outside Marriage. Retrieved from http://www.oecd.org/els/family/SF2_4_Births_outside_marriage_and teenage births.pdf.

Paim, J., Travassos, C., Almedia C., Bahia L., and Macinko J. (2011). The Brazilian health system: history, advances, and challenges. Lancet, 377(9779): 1778-1797.

Pfutze, T. (2014). The effects of Mexico's Seguro Popular health insurance on infant mortality: An estimation with selection on the outcome variable. World Development, 59, pp. $475-486$.

Rasella, D., Harhay, M. O, Pamponet M. L, Aquino R., and Barreto M. L. (2014). Impact of primary health care on mortality from heart and cerebrovascular diseases in Brazil: a nationwide analysis of longitudinal data. British Medical Journal, 349: g4014.

Rasmussen, S.R., Thomsen, J.L., Kilsmark, J., Hvenegaard, A., Engberg, M., and Lauritzen, T. (2007). Preventive health screenings and health consultations in primary care increase life expectancy without increasing costs. Scandinavian Journal of Public Health, 35:365-72.

Ravallion, Martin, Shaohua Chen, and Prem Sangraula. (2007). New evidence on the urbanization of global poverty. Population and Development Review 33, no. 4: 667-701.

Reis, M. (2014). Public primary health care and children's health in Brazil: Evidence from siblings. Journal of Population Economics, 27:421-445.

Ribar DC. (1994). Teenage fertility and high school completion. Review of Economics and Statistics, 76:413-424.

Rocha R and Soares R (2010) Evaluating the impact of community-based health interventions: evidence from Brazil's Family Health Program. Health Economics, 19(S1):S126-S158.

Rottingen JA et al. (2014). Shared responsibilities for health: A coherent global framework for health financing. Final report of the Centre on Global Health Security Working Group on Health Financing. London: Chatham House.

Ruiz F, Amaya L, Venegas S. (2007). Progressive segmented health insurance: Colombian health reform and access to health services. Health Econ, 16(1):3-18. 
Schultz, T. P. (1981). Economics of population, Reading. Addison Wesley, MA.

Sosa-Rubi, S. G., Galarraga, O., and Harris, J. E. (2009). Heterogeneous impact of the "Seguro Popular" program on the utilization of obstetrical services in Mexico, 20012006: a multinomial probit model with a discrete endogenous variable. Journal of Health Economics, 28(1), 20-34.

Somanathan, A., Dao, H. L., and Tien, T. V. (2013). Integrating the poor into universal health coverage in Vietnam. Universal Health Coverage (UNICO) studies series; no.24. Washington, DC: World Bank.

United Nations Sustainable Development Solutions Network. (2014) Health in the framework of sustainable development. Health thematic report. United Nations.

Wagstaff A., Magnus L., Gao J., Xu L., and Qian J. (2009). Extending health insurance to the rural population: An impact evaluation of China's new cooperative medical scheme. Journal of Health Economics, 28(1), 1-19.

Wagstaff A. (2014). We just learned a whole lot more about achieving universal health coverage. World Bank. Retrieved from http://blogs.worldbank.org/developmenttalk/wejust-learned-whole-lot-more-about-achievinguniversal-health-coverage

Walker, M.B., Tekin, E., and Wallace, S. (2009). Teen smoking and birth outcomes. Southern Economic Journal, vol. 75(3), pages 892-907.

World Health Organization (2005). Sustainable health financing, universal coverage and social health insurance [A58/33]. Geneva. Retrieved from http://www.who.int/health_financing/documents/cov-wharesolution5833/en/

World Health Organization (2008), Evaluation of the Organizational Model of Primary Care in Turkey, WHO Regional Office for Europe, Copenhagen.

World Health Organization (2012a). Successful Health System Reforms: The Case of Turkey. A report by WHO Regional Office for Europe, Denmark. Retrieved from http://disab.saglik.gov.tr/yonetim/Uploads/files/kitaplar/Successful\%20Health\%20Syste m\%20Reforms-The\%20Case\%20of\%20Turkey.pdf

World Health Organization (2012b). Turkey Health System Performance Assessment 2011. A report by WHO Regional Office for Europe, Denmark. Retrieved from http://www.euro.who.int/_ data/assets/pdf_file/0004/165109/e95429.pdf

World Health Organization (2014a). Making fair choices on the path to universal health coverage. Final report of the WHO Consultative Group on Equity and Universal Health Coverage. The World Health Organization. Retrieved from http://www.who.int/choice/documents/making_fair_choices/en/. 
World Health Organization (2014b). Better non-communicable disease outcomes:

challenges and opportunities for health systems: Turkey country assessment. No.2, World Health Organization.

World Health Organization (2014c). Children: reducing mortality. World Health Organization Fact sheet no: 178. Retrieved from http://www.who.int/mediacentre/factsheets/fs178/en/.

Worldbank (2012). Turkey Health System Performance Assessment 2011.

Worldbank(2013a). Toward universal coverage: Turkey's green card program for the poor. World Bank UNICO Studies Series No. 18, 75012.

Worldbank (2013b). Turkey performance-based contracting scheme in family medicine-design and achievements. Technical report, 77029-TR.

Yeginsu, C. (2014). Turkey's President Accuses Advocates of Birth Control of Being Traitor. The New York Times. December 22. Retrieved from http://www.nytimes.com/2014/12/23/world/europe/erdogan-turkey-president-sayscontraception-supporters-traitors.html? $\mathrm{r}=0$. 


\section{Figure 1A: Event Study Estimates of the Family Medicine Program on Birth Rates}
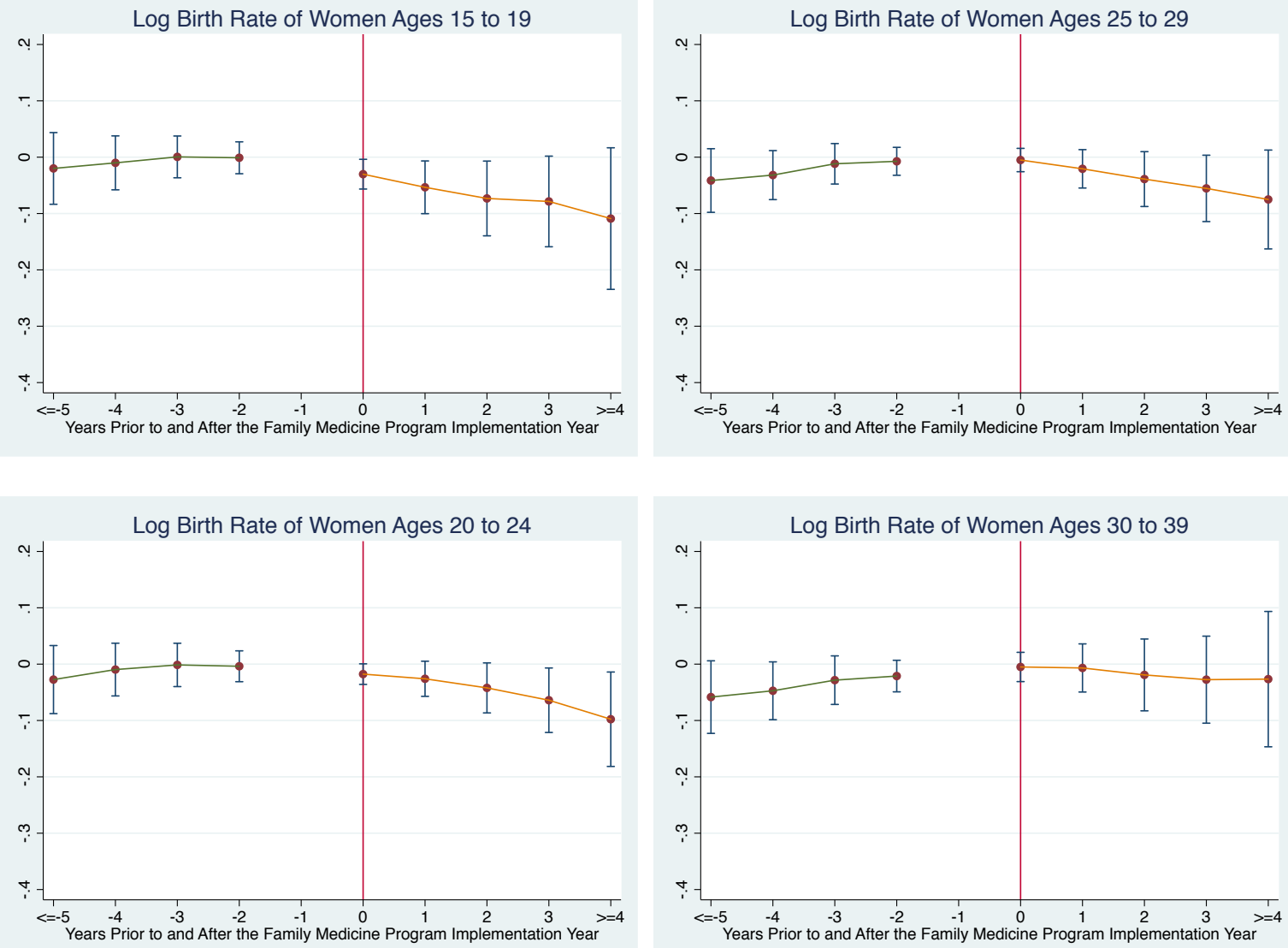

Notes: The figure displays the estimates and $95 \%$ confidence intervals. The reference category is "one year prior to the implementation of the FMP." 
Figure 1B: Event Study Estimates of the Family Medicine Program on Mortality Rates
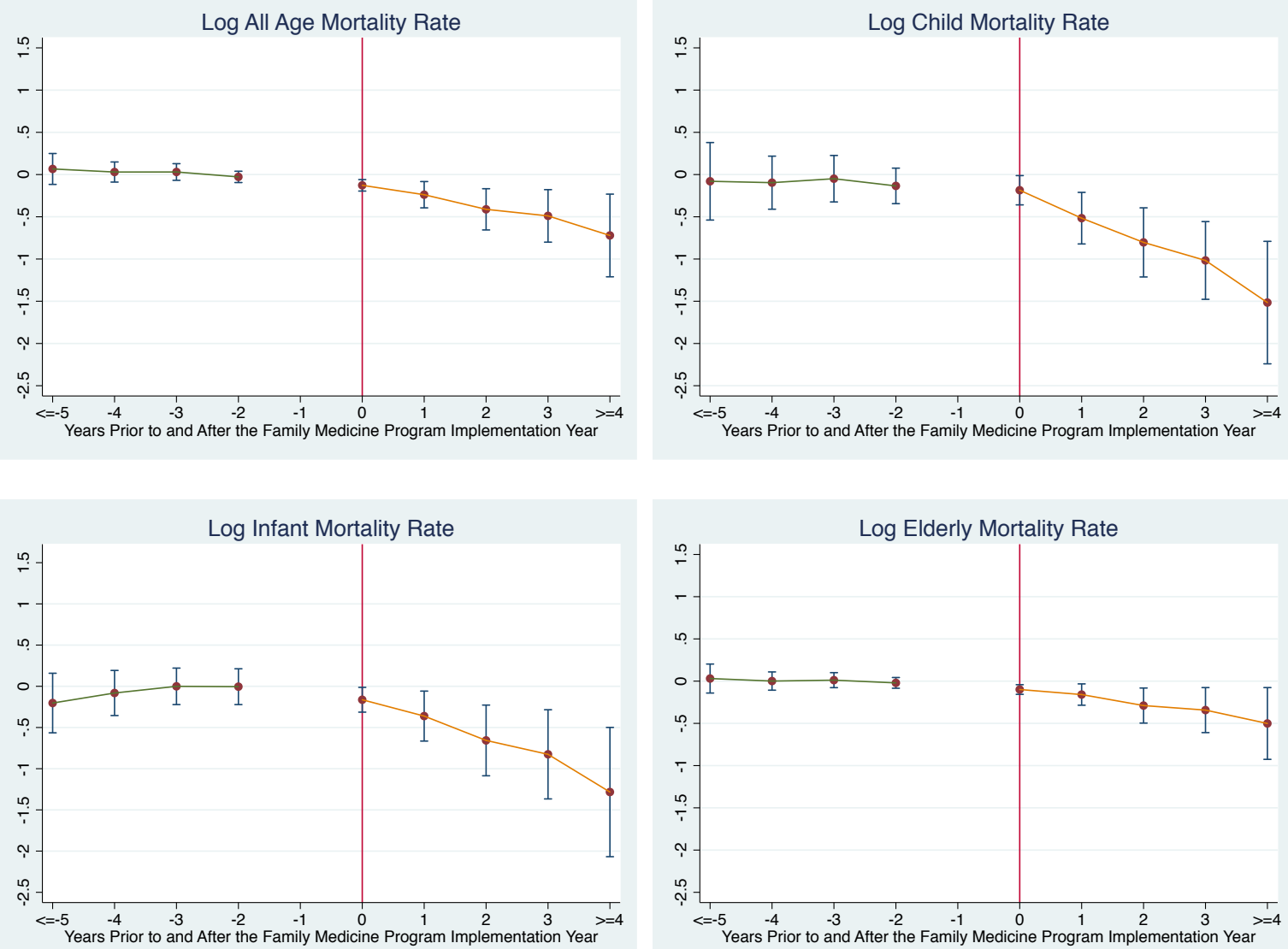

Notes: The figure displays the estimates and $95 \%$ confidence intervals. The reference category is "one year prior to the implementation of the FMP." 
Table 1A. Summary Statistics for Rates of Birth and Mortality by Family Medicine Program Implementation Status

\begin{tabular}{lccc}
\hline & $\begin{array}{c}\text { Full } \\
\text { Sample }\end{array}$ & $\begin{array}{c}\text { Family } \\
\text { Medicine }=1\end{array}$ & $\begin{array}{c}\text { Family } \\
\text { Medicine }=0\end{array}$ \\
\hline Birth Rate of Women Ages 15 to 19 & 36.429 & 30.712 & 39.559 \\
& $(13.724)$ & $(12.825)$ & $(13.189)$ \\
Birth Rate of Women Ages 20 to 25 & 118.528 & 108.449 & 124.094 \\
Birth Rate of Women Ages 25 to 29 & $(31.379)$ & $(30.011)$ & $(30.744)$ \\
& 121.741 & 125.341 & 119.698 \\
Birth Rate of Women Ages 30 to 39 & $(30.682)$ & $(27.433)$ & $(32.222)$ \\
& 63.203 & 66.196 & 61.261 \\
All-Age Mortality & $(29.828)$ & $(23.893)$ & $(32.987)$ \\
Infant Mortality & {$[1,053]$} & {$[412]$} & {$[641]$} \\
& & & 2.881 \\
Mortality Rate of Ages 1 to 4 & 3.633 & 4.867 & $(1.391)$ \\
& $(1.681)$ & $(1.358)$ & {$[641]$} \\
Mortality Rate of Ages 60 and Older & {$[1,053]$} & {$[412]$} & 10.037 \\
& 10.552 & 11.461 & $(6.078)$ \\
& $(5.290)$ & $(3.311)$ & {$[631]$} \\
& {$[1,041]$} & {$[410]$} & 0.531 \\
& 0.607 & 0.742 & $(0.408)$ \\
& $(0.441)$ & $(0.464)$ & {$[594]$} \\
& {$[999]$} & {$[405]$} & 20.443 \\
& 28.071 & 33.735 & $(9.938)$ \\
& $(9.995)$ & $(5.049)$ & {$[641]$} \\
& {$[1,053]$} & {$[412]$} &
\end{tabular}

Notes: Standard deviations are in parenthesis. Number of observations is in brackets. Mean values are weighted by the associated population size for the relevant age group. Because of the missing observations for infant and child mortality, sample sizes for these variables are smaller than the full sample $(\mathrm{N}=1,053)$. 
Table 1B. Summary Statistics for Control Variables by Family Medicine Program Implementation Status

\begin{tabular}{lccc}
\hline & $\begin{array}{c}\text { Full } \\
\text { Sample }\end{array}$ & $\begin{array}{c}\text { Family } \\
\text { Medicine }=1\end{array}$ & $\begin{array}{c}\text { Family } \\
\text { Medicine }=0\end{array}$ \\
\hline Unemployment Rate & 10.962 & 10.565 & 11.338 \\
& $(3.717)$ & $(3.721)$ & $(3.678)$ \\
Motor Vehicles Per Capita & 0.177 & 0.218 & 0.152 \\
& $(0.077)$ & $(0.074)$ & $(0.068)$ \\
GDP Per Capita in Turkish Lira & $11,083.300$ & $13,620.380$ & $9,710.177$ \\
& $(5,087.874)$ & $(5,117.256)$ & $(4,516.788)$ \\
Percent High School & 27.270 & 29.104 & 25.535 \\
& $(8.018)$ & $(8.125)$ & $(7.523)$ \\
Students Per Teacher in Primary Schools & 23.781 & 20.203 & 26.249 \\
& $(6.189)$ & $(4.049)$ & $(6.207)$ \\
Percent College & 9.023 & 10.442 & 7.681 \\
& $(4.089)$ & $(4.081)$ & $(3.619)$ \\
Percent Share of Governing & 0.625 & 0.5958 & 0.6429 \\
Party Seats in Parliament & $(0.175)$ & $(0.174)$ & $(0.173)$ \\
& {$[1,053]$} & {$[412]$} & {$[641]$} \\
\hline
\end{tabular}

Notes: Standard deviations are in parenthesis. Number of observations is in brackets. Mean values are weighted by the associated population size for the relevant age group. 
Table 2A: Estimates of Province Time Varying Characteristics on Family Medicine Program Indicator

\begin{tabular}{|c|c|c|c|c|c|}
\hline & (1) & (2) & (3) & (4) & (5) \\
\hline \multicolumn{6}{|l|}{ Dependent Variable } \\
\hline \multirow[t]{3}{*}{ Log Unemployment Rate } & $-0.084 * *$ & 0.076 & -0.011 & -0.007 & 0.024 \\
\hline & $(0.035)$ & $(0.058)$ & $(0.056)$ & $(0.061)$ & $(0.046)$ \\
\hline & {$[810]$} & [810] & {$[810]$} & [810] & {$[810]$} \\
\hline \multirow[t]{3}{*}{ Log Per-capita Vehicles } & $0.402 * * *$ & 0.083 & -0.019 & -0.012 & -0.017 \\
\hline & $(0.041)$ & $(0.063)$ & $(0.018)$ & $(0.015)$ & $(0.012)$ \\
\hline & {$[1,053]$} & {$[1,053]$} & {$[1,053]$} & {$[1,053]$} & {$[1,053]$} \\
\hline \multirow[t]{3}{*}{ Log Per-capita GDP } & $0.365 * * *$ & $0.072 *$ & 0.003 & 0.002 & 0.005 \\
\hline & $(0.052)$ & $(0.042)$ & $(0.006)$ & $(0.004)$ & $(0.006)$ \\
\hline & {$[648]$} & {$[648]$} & {$[648]$} & [648] & {$[648]$} \\
\hline \multirow[t]{3}{*}{ Log Percent High School } & $0.125 * * *$ & $0.117 * *$ & 0.029 & 0.026 & 0.029 \\
\hline & $(0.032)$ & $(0.050)$ & $(0.025)$ & $(0.026)$ & $(0.020)$ \\
\hline & {$[810]$} & {$[810]$} & [810] & {$[810]$} & [810] \\
\hline \multirow[t]{3}{*}{ Log Percent College } & $0.313 * * *$ & $0.164 * *$ & 0.057 & 0.052 & 0.052 \\
\hline & $(0.058)$ & $(0.077)$ & $(0.045)$ & $(0.053)$ & $(0.038)$ \\
\hline & {$[810]$} & {$[810]$} & {$[810]$} & {$[810]$} & {$[810]$} \\
\hline \multirow[t]{3}{*}{ Log Students Per Teacher } & $-0.061 * * *$ & $-0.083^{* *}$ & -0.013 & -0.009 & 0.008 \\
\hline & $(0.013)$ & $(0.038)$ & $(0.010)$ & $(0.011)$ & $(0.010)$ \\
\hline & [972] & [972] & [972] & [972] & [972] \\
\hline Log Percent Share of Governing & $-0.027 * *$ & -0.007 & -0.013 & -0.012 & 0.001 \\
\hline \multirow[t]{2}{*}{ Party Seats in Parliament } & $(0.011)$ & $(0.030)$ & $(0.012)$ & $(0.011)$ & $(0.015)$ \\
\hline & {$[1,053]$} & {$[1,053]$} & {$[1,053]$} & {$[1,053]$} & {$[1,053]$} \\
\hline \multicolumn{6}{|l|}{ Controls for } \\
\hline Region by Year Fixed Effects & No & Yes & Yes & Yes & Yes \\
\hline Province Fixed Effects & No & No & Yes & Yes & Yes \\
\hline Province Linear Trends & No & No & No & Yes & Yes \\
\hline Province Quadratic Trends & No & No & No & No & Yes \\
\hline
\end{tabular}

Notes: Each cell corresponds to a separate regression, where the "dependent variable" is regressed on Family Medicine Indicator conditional on control variables as indicated above. Regressions are weighted with mean province populations. Robust standard errors clustered at the province level are in parentheses. $*, * *$, and $* * *$ indicate statistical significance at $10 \%, 5 \%$ and $1 \%$, respectively. 
Table 2B: Estimates of Province Time Varying Characteristics on Years since the Family Medicine Program Implemented

\begin{tabular}{|c|c|c|c|c|c|}
\hline & (1) & (2) & (3) & (4) & (5) \\
\hline \multicolumn{6}{|l|}{ Dependent Variable } \\
\hline \multirow{3}{*}{ Log Unemployment Rate } & $-0.031 * *$ & 0.032 & -0.002 & -0.015 & 0.007 \\
\hline & $(0.014)$ & $(0.028)$ & $(0.020)$ & $(0.043)$ & $(0.036)$ \\
\hline & {$[810]$} & {$[810]$} & {$[810]$} & {$[810]$} & {$[810]$} \\
\hline \multirow[t]{3}{*}{ Log Per-capita Vehicles } & $0.106^{* * *}$ & 0.034 & -0.007 & -0.008 & -0.010 \\
\hline & $(0.011)$ & $(0.023)$ & $(0.016)$ & $(0.012)$ & $(0.011)$ \\
\hline & {$[1,053]$} & {$[1,053]$} & {$[1,053]$} & {$[1,053]$} & {$[1,053]$} \\
\hline \multirow[t]{3}{*}{ Log Per-capita GDP } & $0.125^{* * *}$ & 0.026 & -0.005 & -0.006 & -0.004 \\
\hline & $(0.024)$ & $(0.016)$ & $(0.005)$ & $(0.005)$ & $(0.005)$ \\
\hline & {$[648]$} & {$[648]$} & {$[648]$} & [648] & {$[648]$} \\
\hline \multirow[t]{3}{*}{ Log Percent High School } & $0.038 * * *$ & $0.040 * *$ & 0.010 & -0.000 & -0.009 \\
\hline & $(0.009)$ & $(0.017)$ & $(0.009)$ & $(0.029)$ & $(0.025)$ \\
\hline & [810] & {$[810]$} & {$[810]$} & [810] & {$[810]$} \\
\hline \multirow[t]{3}{*}{ Log Percent College } & $0.077 * * *$ & $0.050 *$ & 0.005 & 0.005 & -0.003 \\
\hline & $(0.016)$ & $(0.026)$ & $(0.019)$ & $(0.058)$ & $(0.061)$ \\
\hline & [810] & {$[810]$} & {$[810]$} & {$[810]$} & {$[810]$} \\
\hline \multirow[t]{3}{*}{ Log Students Per Teacher } & $-0.025 * * *$ & $-0.035^{* * *}$ & $-0.013 * * *$ & 0.008 & 0.011 \\
\hline & $(0.004)$ & $(0.013)$ & $(0.004)$ & $(0.009)$ & $(0.010)$ \\
\hline & {$[972]$} & [972] & {$[972]$} & {$[972]$} & {$[972]$} \\
\hline \multirow{3}{*}{$\begin{array}{l}\text { Log Percent Share of Governing } \\
\text { Party Seats in Parliament }\end{array}$} & $-0.006^{*}$ & 0.003 & 0.003 & 0.012 & 0.010 \\
\hline & $(0.003)$ & $(0.011)$ & $(0.006)$ & $(0.017)$ & $(0.015)$ \\
\hline & {$[1,053]$} & {$[1,053]$} & {$[1,053]$} & {$[1,053]$} & {$[1,053]$} \\
\hline \multicolumn{6}{|l|}{ Controls for } \\
\hline Region by Year Fixed Effects & No & Yes & Yes & Yes & Yes \\
\hline Province Fixed Effects & No & No & Yes & Yes & Yes \\
\hline Province Linear Trends & No & No & No & Yes & Yes \\
\hline Province Quadratic Trends & No & No & No & No & Yes \\
\hline
\end{tabular}

Notes: Each cell corresponds to a separate regression, where the "dependent variable" is regressed on Years Since Family Medicine Program Implementation conditional on control variables as indicated above. Regressions are weighted with mean province populations. Standard errors clustered at the province level are in parentheses. ${ }^{*}, *$, and $* * *$ indicate statistical significance at $10 \%, 5 \%$ and $1 \%$, respectively. 
Table 3. The Impact of the Family Medicine Program on Logarithm of Birth Rate

$\begin{array}{cccc}(1) & (2) & (3) & (4) \\ \text { Birth } & \text { Birth } & \text { Birth } & \text { Birth } \\ \text { Rate } & \text { Rate } & \text { Rate } & \text { Rate } \\ 15 \text { to } 19 & 20 \text { to } 24 & 25 \text { to } 29 & 30 \text { to } 39\end{array}$

\begin{tabular}{lcccc} 
Panel A. Controls for Region-by-year Fixed Effects & & & \\
\hline Family Medicine Program & $-0.213^{* * *}$ & $-0.141^{* * *}$ & -0.039 & -0.023 \\
& $(0.072)$ & $(0.042)$ & $(0.029)$ & $(0.042)$ \\
& & & & \\
Observations & 1,053 & 1,053 & 1,053 & 1,053 \\
R-squared & 0.625 & 0.596 & 0.718 & 0.764 \\
\hline
\end{tabular}

Panel B: Controls for Panel A + Province Fixed Effects

\begin{tabular}{lcccc}
\hline Family Medicine Program & $-0.036^{* *}$ & -0.014 & -0.007 & -0.002 \\
& $(0.014)$ & $(0.012)$ & $(0.012)$ & $(0.015)$ \\
& & & & \\
Observations & 1,053 & 1,053 & 1,053 & 1,053 \\
R-squared & 0.822 & 0.695 & 0.637 & 0.731 \\
\hline
\end{tabular}

Panel C: Controls for Panel B + Province-Specific Linear and Quadratic Trends

\begin{tabular}{lcccc}
\hline Family Medicine Program & $-0.036^{* *}$ & -0.014 & -0.012 & -0.013 \\
& $(0.015)$ & $(0.013)$ & $(0.012)$ & $(0.014)$ \\
& & & & \\
Observations & 1,053 & 1,053 & 1,053 & 1,053 \\
R-squared & 0.945 & 0.881 & 0.864 & 0.921 \\
\hline
\end{tabular}

Panel D: Controls for Panel C + Time Varying Province Characteristics

\begin{tabular}{lcccc}
\hline Family Medicine Program & $-0.030^{* *}$ & -0.007 & -0.007 & -0.006 \\
& $(0.012)$ & $(0.009)$ & $(0.009)$ & $(0.011)$ \\
Observations & & & & \\
R-squared & 1,053 & 1,053 & 1,053 & 1,053 \\
\hline
\end{tabular}

Notes: Regressions are weighted with mean province populations for the associated age group. Standard errors, corrected for clustering on the province, are in parentheses. ${ }^{*}, * *$, and $* * *$ indicate statistical significance at $10 \%, 5 \%$ and $1 \%$, respectively. Time varying province characteristics include log of unemployment rate, $\log$ of vehicles per capita, $\log$ of per capita GDP, log of percent high school, $\log$ of percent of college, log of students per teacher in primary schools. 
Table 4: The Impact of the Years Since Family Medicine Program Implementation on Logarithm of Birth Rate

\begin{tabular}{cccc}
$(1)$ & $(2)$ & $(3)$ & $(4)$ \\
Birth & Birth & Birth & Birth \\
Rate & Rate & Rate & Rate \\
15 to19 & 20 to 24 & 25 to 29 & 30 to 39 \\
\hline
\end{tabular}

Panel A: Estimates of Log Birth Rates on Years Since the FMP Implementation

\begin{tabular}{lcccc}
\hline Years Since FMP Implementation & $-0.025^{*}$ & -0.011 & $-0.022 * *$ & $-0.023 * *$ \\
& $(0.015)$ & $(0.013)$ & $(0.011)$ & $(0.010)$ \\
Observations & & & & \\
R-squared & 1,053 & 1,053 & 1,053 & 1,053 \\
\hline
\end{tabular}

Panel B: Estimates of Log Birth Rates on Years Since the FMP Implementation

\begin{tabular}{lcccc}
\hline FMP Year 1 & $-0.024^{* *}$ & -0.008 & -0.006 & -0.010 \\
FMP Year 2 & $(0.011)$ & $(0.009)$ & $(0.010)$ & $(0.011)$ \\
& $-0.045^{*}$ & -0.009 & -0.024 & -0.024 \\
FMP Year 3 & $(0.022)$ & $(0.018)$ & $(0.016)$ & $(0.015)$ \\
& $-0.055^{*}$ & -0.015 & $-0.039^{*}$ & $-0.045^{* *}$ \\
FMP Year 4 & $(0.029)$ & $(0.027)$ & $(0.022)$ & $(0.022)$ \\
& -0.054 & -0.028 & $-0.052^{*}$ & $-0.061^{* *}$ \\
FMP Year 5+ & $(0.039)$ & $(0.035)$ & $(0.030)$ & $(0.027)$ \\
& -0.047 & -0.008 & -0.039 & -0.061 \\
& $(0.051)$ & $(0.048)$ & $(0.040)$ & $(0.037)$ \\
Observations & & & & \\
R-squared & 1,053 & 1,053 & 1,053 & 1,053 \\
\hline N & 0.955 & 0.910 & 0.895 & 0.942 \\
\hline
\end{tabular}

Notes: Regressions are weighted with mean province populations for the associated age group. Standard errors, corrected for clustering on the province, are in parentheses. ${ }^{*}, *$, and $* * *$ indicate statistical significance at $10 \%, 5 \%$ and $1 \%$, respectively. All of the models include the full set of control variables that are specified in the Panel D of Table 3. 
Table 5. The Impact of the Family Medicine Program on Logarithm of Mortality Rates

\begin{tabular}{cccc}
$(1)$ & $(2)$ & $(3)$ & $(4)$ \\
AMR & IMR & CMR & EMR \\
\hline
\end{tabular}

Panel A. Controls for Region-by-year Fixed Effects

\begin{tabular}{lcccc}
\hline Family Medicine Program & $0.176^{* *}$ & $0.254^{*}$ & 0.208 & 0.070 \\
& $(0.085)$ & $(0.131)$ & $(0.156)$ & $(0.085)$ \\
& & & & \\
Observations & 1,053 & 1,041 & 999 & 1,053 \\
R-squared & 0.672 & 0.336 & 0.476 & 0.651 \\
\hline
\end{tabular}

Panel B: Controls for Panel A + Province Fixed Effects

\begin{tabular}{lcccc}
\hline Family Medicine Program & $-0.087^{* * *}$ & $-0.152^{* *}$ & -0.108 & $-0.065^{* *}$ \\
& $(0.030)$ & $(0.058)$ & $(0.076)$ & $(0.025)$ \\
Observations & & & & \\
R-squared & 1,053 & 1,041 & 999 & 1,053 \\
\hline
\end{tabular}

Panel C: Controls for Panel B + Province-Specific Linear and Quadratic Trends

\begin{tabular}{lcccc}
\hline Family Medicine Program & $-0.065^{* *}$ & $-0.151^{* *}$ & -0.080 & $-0.059^{* *}$ \\
& $(0.028)$ & $(0.065)$ & $(0.076)$ & $(0.025)$ \\
Observations & & & & \\
R-squared & 1,053 & 1,041 & 999 & 1,053 \\
\hline
\end{tabular}

Panel D: Controls for Panel C + Time Varying Province Characteristics

\begin{tabular}{lcccc}
\hline Family Medicine Program & $-0.058^{* *}$ & $-0.153 * *$ & -0.062 & $-0.053^{* *}$ \\
& $(0.028)$ & $(0.066)$ & $(0.077)$ & $(0.025)$ \\
& 1,053 & 1,041 & 999 & 1,053 \\
Observations & 0.951 & 0.812 & 0.826 & 0.946 \\
R-squared & & & \\
\hline Notes: Regressions are weighted with mean province populations for the associated age group. & $* *$, and \\
*** indicate statistical significance at $10 \%, 5 \%$ and $1 \%$, respectively. Time varying province characteristics \\
include log of unemployment rate, log of vehicles per capita, log of per capita GDP, log of percent high \\
school, log of percent of college, log of students per teacher in primary schools.
\end{tabular}


Table 6: The Impact of the Years Since Family Medicine Program Implementation on Logarithm of Mortality Rate

\begin{tabular}{cccc}
$(1)$ & $(2)$ & $(3)$ & $(4)$ \\
AMR & IMR & CMR & EMR \\
\hline
\end{tabular}

Panel A: Estimates of Log Mortality Rates on Years Since the FMP Implementation

\begin{tabular}{lcccc}
\hline Years Since FMP Implementation & $-0.106^{* *}$ & $-0.260^{* *}$ & $-0.282^{* * *}$ & $-0.084^{*}$ \\
& $(0.049)$ & $(0.113)$ & $(0.104)$ & $(0.044)$ \\
Observations & & & & \\
R-squared & 1,053 & 1,041 & 999 & 1,053 \\
\hline
\end{tabular}

Panel B: Estimates of Log Mortality Rates on Years Since the FMP Implementation

\begin{tabular}{lcccc}
\hline FMP Year 1 & $-0.054^{* *}$ & $-0.172^{* *}$ & -0.057 & $-0.059^{* *}$ \\
FMP Year 2 & $(0.026)$ & $(0.074)$ & $(0.077)$ & $(0.026)$ \\
& $-0.114^{* *}$ & $-0.331^{* *}$ & $-0.336^{* *}$ & $-0.090^{*}$ \\
FMP Year 3 & $(0.056)$ & $(0.151)$ & $(0.142)$ & $(0.048)$ \\
& $-0.216^{* *}$ & $-0.543^{* *}$ & $-0.512^{* *}$ & $-0.181^{*}$ \\
FMP Year 4 & $(0.102)$ & $(0.216)$ & $(0.232)$ & $(0.092)$ \\
& $-0.236^{*}$ & $-0.662^{* *}$ & $-0.654^{* *}$ & $-0.200^{*}$ \\
FMP Year 5+ & $(0.126)$ & $(0.274)$ & $(0.273)$ & $(0.113)$ \\
& -0.177 & $-0.603^{*}$ & $-0.629^{*}$ & -0.161 \\
& $(0.168)$ & $(0.315)$ & $(0.366)$ & $(0.146)$ \\
Observations & & & & \\
R-squared & 1,053 & 1,041 & 999 & 1,053 \\
\hline
\end{tabular}

Notes: Regressions are weighted with mean province populations for the associated age group. ${ }^{*},{ }^{*}$, and *** indicate statistical significance at $10 \%, 5 \%$ and $1 \%$, respectively. All of the models include the full set of control variables that are specified in the Panel D of Table 5. 


\section{APPENDIX A: Potential Mechanisms through which FMP can Influence Birth and Mortality Rates}

Mechanisms for Birth Rates

The FMP can influence the birth rates through the direct provision of contraception services, such as birth control pills and condoms, as well as changing women's fertility behavior via health counseling and education on reproductive health. Both the program guidelines and our conversations with family physicians suggest that a high priority is given to risky pregnancies, which is defined as pregnancies among women younger than 18 or older than 35 , in less than two-year intervals, and more than four pregnancies in total. Therefore, family physicians specifically target these populations and inform them about the potential risks associated with childbearing, offer them contraception services, and closely monitor pregnant women throughout their pregnancies. ${ }^{32}$ To begin with, easy access to contraception may enable women to avoid undesired pregnancies, especially among the less educated and low-income populations. Improved access to reproductive health services and reproductive health education provided by the family physicians may have a particularly strong effect to reduce teenage fertility. However, close monitoring of pregnant women by family physicians might also increase birth rates potentially through reducing the probability of miscarriages. Lastly, the FMP might change fertility preferences if improvements in adult health due to the program increase labor supply and the returns to labor market participation, which would then increase the opportunity cost of time-intensive activities (Becker, 1981; Schultz, 1981). In summary, the impact of the FMP on the birth rate is likely to be age-specific

\footnotetext{
${ }^{32}$ Although women's health and family planning services are formally incorporated in the program's definition, the FMP does not provide any type of fertility treatments.
} 
and theoretically ambiguous due to multiple channels with opposing directions, with the likely exception for teenagers for whom the impact is predicted to be negative.

\section{Mechanisms for Mortality Rates}

The FMP has dramatically improved the quality of and access to primary care in terms of preventive, curative, and rehabilitative services especially for pregnant women, new mothers, infants, children, and the elderly, whose healthcare needs are the major focus of the FMP (Worldbank, 2013b). ${ }^{33}$ According to WHO (2014c), majority of the infant and child deaths are due to pregnancy and delivery related complications, infections during pregnancy, poor maternal health, infectious diseases including pneumonia and diarrhea, and lack of nutrition, especially in developing countries. These factors are responsible for the majority of child deaths in Turkey as well (Demirel et al. 2013). Child and infant deaths due to the factors above could be significantly reduced by interventions during pregnancy and delivery through the use of prenatal and postnatal care, including doctor visits, screening for diseases and infections, proper intake of nutrients, and the provision of immunizations, which are all among the major services provided by the FMP. As outlined in the program guidelines, family physicians prioritize the administration of prenatal and postnatal care services for women and children (especially for economically disadvantaged households), delivery services for women (especially in rural areas), and monitoring system for child health and development. For example, women 15-49 years old are followed-up twice a year by family physicians in order to detect pregnancies at an early stage and provide counseling services on family

\footnotetext{
${ }^{33}$ Unfortunately, we are not able to evaluate the impact of the FMP on maternal mortality because such data are not available at the province-year level for the analysis period.
} 
planning. Family physicians urge pregnant women to have at least four prenatal care visits during pregnancy —at least one visit in the first trimester, two visits in the second, and one visit in the third trimester. Pregnant women are screened for hypertension (high blood pressure), proteinuria (abnormal amount of protein in urine), and glycosuria (the excretion of glucose into the urine) in each prenatal care visit. Furthermore, they are administered hemoglobin tests in the first trimester and platelet count in the third trimester in order to screen for several health conditions, such as anemia, and excess bleeding or clotting. The family physicians also screen infants for congenital hypothyroidism and biotinidase deficiency, phenylketonuria, and hearing loss. Moreover, a variety of new neonatal services are introduced with the FMP, including neonatal emergency care and air ambulance for maternal emergencies. The improved maternal and infant healthcare services provide prevention, screening, diagnosis, and treatment services, which target the major causes of maternal and infant mortality.

Another feature of the FMP that could help reduce child mortality is the free delivery of nutritional supplements. Anemia, especially iron-deficiency anemia, is the most common form of malnutrition, particularly in pregnant women and young children in developing countries. ${ }^{34},{ }^{35}$ These complications are preventable in pregnant women who receive iron and folic acid supplements as part of their prenatal care. The FMP delivers free iron and folic acid supplements to pregnant women in order to prevent anemia, which in turn improves maternal and infant health.

\footnotetext{
${ }^{34}$ In pregnant women, iron-deficiency is associated with perinatal, prenatal, and maternal mortality, low birth weight, premature births, and increased risk of sepsis; while folate-deficiency (or folic acid deficiency) anemia is linked to certain types of birth defects, such as neural tube abnormalities in the infant and low birth weight. See http://www.who.int for more detailed information.

${ }^{35} \mathrm{See}$ http://www.who.int/nutrition/topics/ida/en/.
} 
Additionally, to reduce the prevalence of vaccine preventable infectious diseases, the FMP pays close attention to achieving universal immunization coverage. For example, the program incentivizes the family medicine providers by making deductions from their monthly salary if they fail to achieve high immunization coverage rates of registered children (Worldbank, 2013b). Moreover, family physicians are expected to inform families about immunization schedule and delivery and to educate them about the consequences of not immunizing their children.

Family physicians might also change health behaviors of mothers by providing information on the importance of hygiene and encouraging basic sanitation techniques to prevent infectious diseases. They can also teach parents how to treat and prevent diarrhea using simple methods, which might in turn reduce mortality among young children. Another potential mechanism is the first aid treatment services provided by the FMP in the event of accidents and injuries.

Because non-communicable diseases (NCDs) are a major cause of death in Turkey, provision of primary healthcare might reduce the elderly mortality rates by prevention, early detection and management, and treatment of NCDs. Early detection and effective management of NCDs through primary healthcare have been shown to reduce mortality and increase life expectancy (Bailey and Goodman-Bacon, 2015; Levene et al., 2010; Rasella et al. 2014; Rasmussen et al., 2007).

Lastly, another potential channel through which primary care access may lower mortality is to reduce the incidence of modifiable risk factors, such as smoking, unhealthy diet, physical inactivity, and excessive alcohol consumption. Family physicians might change individual behaviors by promoting healthy lifestyles and informing the 
patients about the adverse health consequences of risk factors (Goldman and Cook, 1984;

Nolte and Mckee, 2004;). 


\section{Appendix Table 1: Family Medicine Program Implementation Year and the Number of Family Physicians Per 10 Thousand Populations in 2013}

\begin{tabular}{|c|c|c|c|c|c|}
\hline Province & $\begin{array}{c}\text { Year of } \\
\text { Implementation }\end{array}$ & $\begin{array}{c}\text { Family } \\
\text { Physicians } \\
\text { Per 10K } \\
\text { Populations }\end{array}$ & Province & $\begin{array}{c}\text { Year of } \\
\text { Implementation }\end{array}$ & $\begin{array}{c}\text { Family } \\
\text { Physicians } \\
\text { Per 10K } \\
\text { Populations }\end{array}$ \\
\hline Duzce & 2005 & 2.76 & Artvin & 2010 & 3.01 \\
\hline Adiyaman & 2006 & 3 & Aydin & 2010 & 2.83 \\
\hline Bolu & 2006 & 3.07 & Balikesir & 2010 & 2.82 \\
\hline Denizli & 2006 & 2.86 & Batman & 2010 & 2.79 \\
\hline Edirne & 2006 & 2.89 & Bingol & 2010 & 2.98 \\
\hline Eskisehir & 2006 & 2.8 & Bitlis & 2010 & 2.7 \\
\hline Gumushane & 2006 & 2.97 & Canakkale & 2010 & 2.69 \\
\hline Amasya & 2007 & 3.14 & Diyarbakir & 2010 & 2.64 \\
\hline Bartin & 2007 & 3.17 & Erzincan & 2010 & 3.18 \\
\hline Elazig & 2007 & 3.04 & Gaziantep & 2010 & 2.66 \\
\hline Isparta & 2007 & 3.11 & Giresun & 2010 & 2.87 \\
\hline Izmir & 2007 & 2.8 & Hakkari & 2010 & 2.34 \\
\hline Samsun & 2007 & 2.86 & Hatay & 2010 & 2.71 \\
\hline Sinop & 2007 & 2.84 & Igdir & 2010 & 2.84 \\
\hline Adana & 2008 & 2.83 & Istanbul & 2010 & 2.57 \\
\hline Bayburt & 2008 & 3.44 & Kahramanmaras & 2010 & 2.88 \\
\hline Bilecik & 2008 & 3.02 & Kars & 2010 & 2.86 \\
\hline Burdur & 2008 & 3.11 & Kilis & 2010 & 2.8 \\
\hline Cankiri & 2008 & 2.57 & Kirklareli & 2010 & 2.82 \\
\hline Corum & 2008 & 3.18 & Kocaeli & 2010 & 2.79 \\
\hline Erzurum & 2008 & 3.12 & Konya & 2010 & 2.79 \\
\hline Karabuk & 2008 & 2.95 & Kutahya & 2010 & 3.09 \\
\hline Karaman & 2008 & 3.19 & Malatya & 2010 & 2.81 \\
\hline Kastamonu & 2008 & 2.83 & Mardin & 2010 & 2.54 \\
\hline Kayseri & 2008 & 2.91 & Mersin & 2010 & 2.86 \\
\hline Kirikkale & 2008 & 3.09 & Mugla & 2010 & 2.84 \\
\hline Kirsehir & 2008 & 3.31 & Mus & 2010 & 2.71 \\
\hline Manisa & 2008 & 2.94 & Nevsehir & 2010 & 3.01 \\
\hline Osmaniye & 2008 & 2.91 & Nigde & 2010 & 2.97 \\
\hline Tunceli & 2008 & 2.93 & Ordu & 2010 & 2.68 \\
\hline Yalova & 2008 & 2.5 & Sakarya & 2010 & 2.81 \\
\hline Bursa & 2009 & 2.75 & Sanliurfa & 2010 & 2.76 \\
\hline Rize & 2009 & 2.89 & Siirt & 2010 & 2.71 \\
\hline Trabzon & 2009 & 3.07 & Sirnak & 2010 & 2.76 \\
\hline Usak & 2009 & 3.12 & Sivas & 2010 & 2.84 \\
\hline Afyonkarahisar & 2010 & 2.9 & Tekirdag & 2010 & 2.76 \\
\hline Agri & 2010 & 2.69 & Tokat & 2010 & 2.91 \\
\hline Aksaray & 2010 & 2.87 & Van & 2010 & 2.64 \\
\hline Ankara & 2010 & 2.63 & Yozgat & 2010 & 3.02 \\
\hline Antalya & 2010 & 2.67 & Zonguldak & 2010 & 2.88 \\
\hline Ardahan & 2010 & 3.02 & & & \\
\hline
\end{tabular}

Note: Information on the Family Medicine Program is obtained from the Public Health Institute of Turkey. 
Appendix Table 2A: Estimates of Family Medicine Program Indicator on Time Varying Province Level Observable Characteristics

\begin{tabular}{lccccc}
\hline & $(1)$ & $(2)$ & $(3)$ & $(4)$ & $(5)$ \\
\hline & & & & & \\
Log of Unemployment Rate & -0.024 & 0.055 & -0.001 & 0.015 & -0.006 \\
& $(0.069)$ & $(0.048)$ & $(0.056)$ & $(0.083)$ & $(0.087)$ \\
Log of Vehicles Per Capita & -0.037 & -0.017 & -0.093 & -0.236 & -0.280 \\
& $(0.031)$ & $(0.032)$ & $(0.092)$ & $(0.205)$ & $(0.211)$ \\
Log of GDP & $0.498^{* * *}$ & -0.001 & 0.072 & 0.080 & -0.108 \\
& $(0.073)$ & $(0.097)$ & $(0.093)$ & $(0.109)$ & $(0.122)$ \\
Log of High school Rate & $-0.697 * * *$ & 0.070 & 0.036 & 0.033 & 0.067 \\
& $(0.175)$ & $(0.061)$ & $(0.056)$ & $(0.081)$ & $(0.065)$ \\
Log of College Rate & $0.247^{* * *}$ & 0.040 & 0.045 & 0.067 & 0.063 \\
& $(0.083)$ & $(0.046)$ & $(0.046)$ & $(0.063)$ & $(0.069)$ \\
Log of Students Per Teacher & -0.079 & $-0.222^{* *}$ & -0.144 & -0.118 & 0.084 \\
& $(0.164)$ & $(0.098)$ & $(0.104)$ & $(0.129)$ & $(0.109)$ \\
Log Percent Share of Governing & -0.050 & 0.040 & -0.028 & -0.053 & 0.031 \\
Party Seats in Parliament & $(0.169)$ & $(0.122)$ & $(0.089)$ & $(0.108)$ & $(0.216)$ \\
& & & & & \\
Observations & 1,053 & 1,053 & 1,053 & 1,053 & 1,053 \\
R-squared & 0.516 & 0.865 & 0.886 & 0.888 & 0.918 \\
F-test & 18.39 & 2.020 & 1.547 & 1.228 & 0.627 \\
F-test P-value & 0.000 & 0.0625 & 0.164 & 0.298 & 0.732 \\
\hline Controls for & & & & & \\
Region by Year Fixed Effects & No & Yes & Yes & Yes & Yes \\
Province Fixed Effects & No & No & Yes & Yes & Yes \\
Province Linear Trends & No & No & No & Yes & Yes \\
Province Quadratic Trends & No & No & No & No & Yes \\
\hline
\end{tabular}

Notes: Regressions are weighted with mean province populations. Standard errors, corrected for clustering on the province, are in parentheses. *,**, and $* * *$ indicate statistical significance at $10 \%, 5 \%$ and $1 \%$, respectively. 
Appendix Table 2B: Estimates of Years Since Time of Family Medicine Program

Implementation on Time Varying Province Level Observable Characteristics

\begin{tabular}{lccccc}
\hline & $(1)$ & $(2)$ & $(3)$ & $(4)$ & $(5)$ \\
\hline Log of Unemployment Rate & & & & & \\
& 0.112 & $0.458^{*}$ & 0.123 & -0.082 & -0.073 \\
Log of Vehicles Per Capita & $(0.300)$ & $(0.233)$ & $(0.181)$ & $(0.112)$ & $(0.139)$ \\
& -0.109 & -0.042 & -0.303 & -0.114 & -0.235 \\
Log of GDP & $(0.112)$ & $(0.177)$ & $(0.640)$ & $(0.260)$ & $(0.377)$ \\
& $1.256^{* * *}$ & -0.399 & -0.366 & 0.002 & -0.015 \\
Log of High school Rate & $(0.246)$ & $(0.413)$ & $(0.235)$ & $(0.110)$ & $(0.190)$ \\
& $-1.662^{* * *}$ & $0.659^{*}$ & $0.572 * *$ & -0.040 & -0.057 \\
Log of College Rate & $(0.567)$ & $(0.393)$ & $(0.278)$ & $(0.090)$ & $(0.105)$ \\
& 0.447 & 0.102 & 0.048 & 0.001 & 0.016 \\
Log of Students Per Teacher & $(0.311)$ & $(0.230)$ & $(0.164)$ & $(0.070)$ & $(0.139)$ \\
& $-1.138^{* *}$ & $-1.497 * * *$ & $-1.279^{* * *}$ & 0.185 & 0.244 \\
Log Percent Share of Governing & $(0.514)$ & $(0.560)$ & $(0.446)$ & $(0.179)$ & $(0.225)$ \\
Party Seats in Parliament & -0.116 & 0.575 & 0.487 & 0.192 & 0.273 \\
& $(0.695)$ & $(0.724)$ & $(0.474)$ & $(0.285)$ & $(0.435)$ \\
Observations & & & & & \\
R-squared & 1,053 & 1,053 & 1,053 & 1,053 & 1,053 \\
Joint F-test & 0.654 & 0.855 & 0.917 & 0.986 & 0.987 \\
Joint F-test P-value & 8.735 & 2.144 & 1.748 & 0.632 & 0.696 \\
\hline Controls for & 0.000 & 0.048 & 0.110 & 0.728 & 0.675 \\
Region by Year Fixed Effects & & & & & \\
Province Fixed Effects & No & Yes & Yes & Yes & Yes \\
Province Linear Trends & No & No & Yes & Yes & Yes \\
Province Quadratic Trends & No & No & No & Yes & Yes \\
\hline
\end{tabular}

Notes: Regressions are weighted with mean province populations. Standard errors, corrected for clustering on the province, are in parentheses. ${ }^{*},{ }^{*}$, and $* * *$ indicate statistical significance at $10 \%, 5 \%$ and $1 \%$, respectively. 
Appendix Table 3. The Impact of the Family Medicine Program on Birth Rates By Baseline Birth Rates

\begin{tabular}{|c|c|c|c|c|}
\hline & $\begin{array}{c}1) \\
\text { Birth } \\
\text { Rate } \\
15 \text { to19 } \\
\end{array}$ & $\begin{array}{c}(2) \\
\text { Birth } \\
\text { Rate } \\
20 \text { to } 24 \\
\end{array}$ & $\begin{array}{c}(3) \\
\text { Birth } \\
\text { Rate } \\
25 \text { to } 29 \\
\end{array}$ & $\begin{array}{c}(4) \\
\text { Birth } \\
\text { Rate } \\
30 \text { to } 39 \\
\end{array}$ \\
\hline Family Medicine Program & $\begin{array}{l}-0.03113 \\
(0.03400)\end{array}$ & $\begin{array}{c}0.04228 \\
(0.05119)\end{array}$ & $\begin{array}{c}0.04950 \\
(0.03848)\end{array}$ & $\begin{array}{l}-0.00003 \\
(0.02241)\end{array}$ \\
\hline (Baseline 15 to 19 Birth Rate)*FMP & $\begin{array}{c}0.00003 \\
(0.00087)\end{array}$ & & & \\
\hline (Baseline 20 to 24 Birth Rate) *FMP & & $\begin{array}{l}-0.00043 \\
(0.00043)\end{array}$ & & \\
\hline (Baseline 25 to 29 Birth Rate)*FMP & & & $\begin{array}{l}-0.00048 \\
(0.00032)\end{array}$ & \\
\hline (Baseline 39 to 39 Birth Rate)*FMP & & & & $\begin{array}{l}-0.00011 \\
(0.00033)\end{array}$ \\
\hline Observations & 1,053 & 1,053 & 1,053 & 1,053 \\
\hline R-squared & 0.954 & 0.908 & 0.892 & 0.940 \\
\hline F-test of joint significance & 3.185 & 0.789 & 1.454 & 0.242 \\
\hline F-test P-value & 0.046 & 0.458 & 0.240 & 0.786 \\
\hline
\end{tabular}


Appendix Table 4. The Impact of the Family Medicine Program on Mortality By Baseline Mortality Rates

\begin{tabular}{|c|c|c|c|c|}
\hline & $\begin{array}{c}(1) \\
\text { AMR }\end{array}$ & $\begin{array}{l}(2) \\
\text { IMR }\end{array}$ & $\begin{array}{c}(3) \\
\text { CMR }\end{array}$ & $\begin{array}{c}(4) \\
\text { EMR }\end{array}$ \\
\hline Family Medicine Program & $\begin{array}{c}0.231 * * \\
(0.093)\end{array}$ & $\begin{array}{c}0.688 * * * \\
(0.170)\end{array}$ & $\begin{array}{c}0.429 * * * \\
(0.133)\end{array}$ & $\begin{array}{c}0.248 * * * \\
(0.084)\end{array}$ \\
\hline (Baseline $A M R) * F M P$ & $\begin{array}{c}-0.091 * * * \\
(0.025)\end{array}$ & & & \\
\hline (Baseline IMR)*FMP & & $\begin{array}{c}-0.086 * * * \\
(0.016)\end{array}$ & & \\
\hline (Baseline $C M R$ )*FMP & & & $\begin{array}{c}-0.952 * * * \\
(0.213)\end{array}$ & \\
\hline (Baseline EMR)*FMP & & & & $\begin{array}{c}-0.015 * * * \\
(0.003)\end{array}$ \\
\hline Observations & 1,053 & 1,041 & 986 & 1,053 \\
\hline R-squared & 0.951 & 0.821 & 0.825 & 0.947 \\
\hline F-test of joint significance & 9.789 & 15.25 & 11.02 & 13.78 \\
\hline F-test P-value & 0.000 & 0.000 & 0.000 & 0.000 \\
\hline
\end{tabular}

Regressions are weighted with mean province populations for the associated age group. Standard errors, corrected for clustering on the province, are in parentheses. ${ }^{*}, * *$, and $* * *$ indicate statistical significance at $10 \%, 5 \%$ and $1 \%$, respectively. All of the models include the full set of control variables that are specified in the Panel D of Table 5. 